\title{
ITINERARIO DE UNA COMUNIDAD \\ EXCLAUSTRADA. LOS RELIGIOSOS DEL \\ COLEGIO DE GUADALUPE FRENTE A LA \\ LEY DE NACIONALIZACIÓN DE BIENES \\ ECLESIÁSTICOS (1859-1908)"
}

\author{
Héctor Strobel del Moral \\ El Colegio de México
}

INTRODUCCIÓN

$\mathrm{F}$ ste trabajo tiene como propósito estudiar los sucesos desColegio Apostólico de Propaganda Fide de Nuestra Señora de Guadalupe, Zacatecas (en adelante Colegio de Guadalupe). Ésta se verificó a principios de agosto de 1859, como consecuencia de la ley del 12 de julio del mismo año, conocida como ley de nacionalización de bienes eclesiásticos, que expropió las propiedades de todas las órdenes masculinas del país y obligó a sus frailes a abandonar sus conventos, el hábito y la vida

Fecha de recepción: 19 de julio de 2018

Fecha de aceptación: 21 de febrero de 2019

* Detrás de este artículo se halla el apoyo de varias personas. Agradezco las valiosas sugerencias de la Dra. Anne Staples, de la Dra. Erika Pani, del Dr. Pablo Mijangos, del Mtro. Pedro Espinoza Meléndez y del Mtro. José Luis Quezada Lara. Así mismo, por sus atenciones en Zacatecas, Jalisco y Ciudad de México, quedo en deuda con la Dra. Elisa Cárdenas Ayala, con la Mtra. Maritza Gómez Revuelta, con la Mtra. Rosa María Franco Velasco, con el padre fray Raúl Robledo Delgadillo, con Claudio J. Ortiz y con Sofía Zamorano. 
común. La exclaustración provocó un complejo fenómeno que implicó cuestiones políticas y de derecho canónico. Además, dio principio a un largo proceso de resistencias, reacomodos y estrategias discursivas por parte de los religiosos que se extendió hasta el siglo xx. En particular, nos interesaremos por estudiar qué fue lo que hizo la comunidad del Colegio de Guadalupe en los primeros meses de su exclaustración. Tal acontecimiento no fue nada sencillo para los frailes, pues involucró temas de índole moral que los dejó entre la espada y la pared, teniendo que elegir entre los votos que habían jurado y la obediencia al gobierno. Tanto los franciscanos que incumplieron sus votos, como los que continuaron observándolos, tuvieron que utilizar diversos argumentos para justificar sus actos. Además de este aspecto, estudiaremos lo que hicieron los frailes con sus vidas los años siguientes, los lugares a donde se dirigieron y las condiciones de vida en las que terminaron. Un último asunto que también abordaremos será el de los debates en torno a la autoridad a la que debían obedecer los religiosos exclaustrados que se negaron a cumplir la ley del 12 de julio.

A la fecha, no se ha realizado ningún trabajo en específico sobre los procesos de exclaustración de frailes en México. ${ }^{1}$ Existen investigaciones que los han abordado tangencialmente, como parte de estudios generales sobre la Iglesia mexicana o la Reforma. Entre ellos, destacan los de Jan Bazant, Jacqueline Covo y María Eugenia García Ugarte. ${ }^{2}$ De la exclaustración en el Colegio de Guadalupe tampoco existen trabajos en especial. El único que ha realizado algo vinculado a este tema ha sido

1 Durante la década de 1990, Elisa Speckman se dedicó al estudio de la exclaustración de las órdenes femeninas, decretada hasta el 26 de febrero de 1863 y distinta a la de los frailes. SPECKMAN, "Las órdenes femeninas en el siglo XIX", pp. 15-40; "Congregaciones femeninas en la segunda mitad del siglo XIX"; "Los conventos de monjas y las leyes de febrero de 1861".

2 Bazant, Los bienes de la Iglesia en México; Covo, Las ideas de la Reforma en México, pp. 522-524; García Ugarte, Poder político y religioso, pp. 835-841. 
Salvador Moreno Basurto. Sin embargo, su investigación es más bien de orden historiográfico, pues se limitó a revisar la forma en que la exclaustración fue interpretada por tres autores de la segunda mitad del siglo xIx y principios del xx. ${ }^{3}$ Existen, por su parte, historias generales del convento escritas por sus cronistas que narran la exclaustración en el Colegio. La forma en la que lo hacen, sin embargo, es sumamente descriptiva y subjetiva. Entre estas obras destacan la de Cuauhtémoc Sánchez Esparza y las de los frailes José Francisco Sotomayor y Ángel Tiscareño. ${ }^{4}$

El hecho de que se le haya prestado poca atención a nuestro objeto de estudio no es fortuito. Los historiadores del arte han descalificado la exclaustración, considerándola un momento "despreciable" que puso en peligro el patrimonio cultural del convento. ${ }^{5} \mathrm{El}$ grueso de la literatura que se ha escrito sobre el Colegio ha partido de enfoques artísticos y conservacionistas. Esto se ha hecho de manera justificada, pues la amplia riqueza de su arquitectura, de las obras de arte que resguarda y de su acervo bibliográfico, lo ha hecho merecedor de estudios detallados sobre estos aspectos. Dentro de esta perspectiva, la exclaustración y nacionalización del convento es vista sólo con desdén y culpa por las pérdidas sufridas. ${ }^{6}$

${ }^{3}$ Moreno Basurto, Salvador, "Una historia desangrada para un convento rosa”, pp. 329-338.

${ }^{4}$ Sotomayor, José Francisco, Historia del apostólico Colegio de Nuestra Señora de Guadalupe de Zacatecas, pp. 276-347; Tiscareño, El Colegio de Guadalupe, pp. 6-375; Esparza SÁnchez, Compendio histórico del Colegio, pp. 93-108.

5 Sescosse, El Colegio de Guadalupe de Zacatecas.; Ahued Valenzuela, El libro del histórico y virreinal, p. 13.

6 Sescosse, El Colegio de Guadalupe; Ahued Valenzuela, El libro del histórico y virreinal; CARREÑo VELÁzQUEZ (coord.), Los libros en los senderos de la fe; GonZÁLEz Quĩ̃ones (ed.), La biblioteca conventual del Colegio de Propaganda Fide de Nuestra Señora de Guadalupe Zacatecas; EsParza VALDivia, Colegio y convento de Guadalupe; EsParza Valdivia, Guia histórica de la Orden Franciscana Seglar de Guadalupe; LóPEZ DE LARA, Guadalupe, guía de un viejo convento; MAZA, "El arte en la ciudad de Zacatecas", pp. 5-16. 
El presente artículo se divide en cuatro apartados. En el primero y en el segundo exponemos el contexto en el cual se halló inserto el Colegio de Guadalupe, la razón de la crisis por la cual pasó hacia mediados del siglo xIx y el impacto de las políticas liberales en el convento y en la sociedad zacatecana. En los siguientes dos apartados explicamos el complicado proceso que tuvo que sobrellevar la comunidad guadalupana luego de su exclaustración, así como las estrategias que empleó para soslayar los problemas que enfrentó.

DEL COLEGIO DE PROPAGANDA FIDE

“MÁS IMPORTANTE DEL MUNDO” A LA CRISIS DEL XIX

La Congregación de Propaganda Fide fue creada por bula papal en 1622. Su objetivo fue establecer una serie de centros misioneros que respondieran directamente a la Santa Sede bajo la forma de colegios, con el fin de procurar la mejor instrucción a los religiosos para predicar entre fieles e infieles. Los colegios de América fueron encargados a la orden franciscana. El primero que fundaron fue el de Querétaro, en 1683. Su éxito y popularidad fueron tales que pronto se autorizó la creación de más. Así, en 1707, se creó en las cercanías de la ciudad de Zacatecas el Colegio de Guadalupe, en torno al cual se conformó con el tiempo una villa, a la que se bautizó con el mismo nombre, Guadalupe. ${ }^{7}$ Los demás colegios establecidos en la Nueva España fueron, consecutivamente, los de Guatemala, Ciudad de México, Pachuca, Orizaba y Zapopan.

La red de colegios de América desempeñó un servicio importante a la corona española, particularmente por tomar parte en la expansión y presencia del imperio en las fronteras y en territorios de escasa población hispana. $\mathrm{Al}$ igual que otras congregaciones misioneras, constituyeron la punta de lanza de la colonización,

7 Escandón, “La estrategia imperial”, pp. 46, 50-51. 
Imagen 1

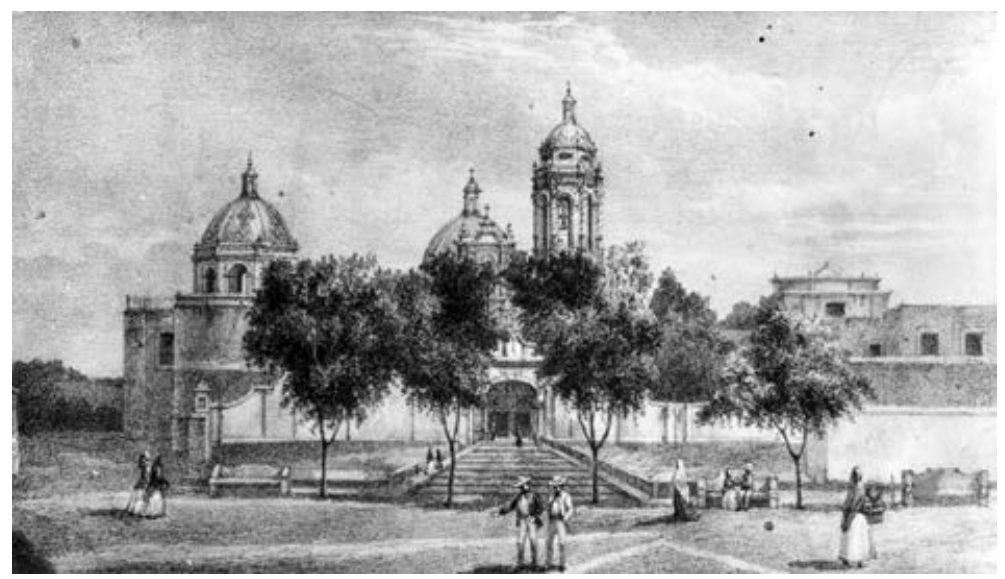

El Colegio de Guadalupe hacia 1872.

Fuente: BCRTA, Fot., Colección Federico Sescosse, c. 3.

poblamiento e incorporación de territorios a los dominios de la monarquía, precediendo la traza, los ayuntamientos y demás instituciones. Cuando los jesuitas fueron expulsados de la Nueva España, casi todas sus misiones fueron repartidas entre los colegios del virreinato. Así, de contar con cerca de 80 misiones antes de 1767 , pasaron a tener 179 . Por esta misma razón, para la fecha precisaron multiplicar su personal. ${ }^{8}$

De todos los colegios, el más poblado y con mayor cantidad de misiones en el continente americano, e incluso en el mundo, fue precisamente el de Guadalupe. A lo largo de su existencia recibió cuantiosas limosnas y donaciones, llegando a hacerse de un capital artístico y bibliográfico significativo, parte del cual aún puede ser admirado. En varias ocasiones se llegó a afirmar que era el convento "más importante del mundo". Hacia la década

\footnotetext{
${ }^{8}$ Morales Valerio, “Guadalupe Zacatecas”, pp. 60, 62; Escandón, “La estrategia imperial”, p. 51.
} 
de 1780, su población ascendía a 373 individuos, repartida entre el Colegio y sus misiones. De ellos, 276 eran frailes, 56 novicios, 17 legos, 14 donados y 10 muchachos de hospicio. Para la fecha, el convento poseía tres hospicios y más de 50 misiones, que iban desde Zacatecas hasta California y Texas. En contraste, el personal de cada uno de los demás colegios del virreinato no superaba las 100 personas. ${ }^{9}$ Décadas más tarde, la guerra de independencia mermó la población de los colegios de la Nueva España. Hacia 1822, la del de Guadalupe se redujo a 255 individuos, lo cual no evitaba que siguiera siendo importante. Otros colegios, como el de Querétaro y el de Pachuca, contaban para entonces con tan sólo 66 y 45 religiosos, respectivamente. Por su parte, el total de los franciscanos de la Provincia de San Francisco de Zacatecas apenas ascendía a 157 frailes. ${ }^{10}$

Los primeros años de vida independiente de México significaron otro declive importante para las órdenes religiosas. Durante la década de 1830, las críticas de la esfera civil contra la Iglesia, presentes al menos desde mediados del siglo xviII según Brian Connaughton, comenzaron a acentuarse. Estas no se dirigieron tan sólo contra las prácticas religiosas, sino que también respaldaron el derecho de las autoridades civiles a permitirlas o prohibirlas. ${ }^{11} \mathrm{La}$ administración liberal del vicepresidente Valentín Gómez Farías (1833-1834) afectó bastante al clero, pero mucho más al regular que al secular. Por decreto del 6 de noviembre de 1833, se eliminó la coacción civil para el cumplimiento de los votos monásticos. Esto, aunado a otras leyes, ocasionó otra sensible reducción de frailes en todas las órdenes religiosas del

\footnotetext{
9 Para la misma década, el Colegio de Querétaro y sus misiones tenían 90 frailes, el de la Ciudad de México 96 y el de Pachuca 70. Esparza Sánchez, Compendio histórico del Colegio, pp. 131-132.

10 Esparza Sánchez, Compendio histórico del Colegio, p. 132.

${ }^{11}$ Connaughton, "De la tensión de compromiso al compromiso", pp. 7376; Hale, El liberalismo mexicano; Mijangos, Entre Dios y la República, pp. 223-236.
} 
país. De 1831 a 1860, por ejemplo, en la provincia franciscana de Santiago Xalisco, tan sólo 71 individuos recibieron hábito, de los cuales 30 pronunciaron votos y, de éstos, sólo 17 se ordenaron sacerdotes. ${ }^{12}$ La cantidad de novicios en el Colegio de Guadalupe también se vio considerablemente disminuida, de manera que para finales de la década de 1850, la comunidad únicamente contaba con cuatro. Así mismo, las órdenes mendicantes dejaron de percibir las cuantiosas limosnas de antaño. Los franciscanos de todo el país, que dependían en gran medida de ellas, se vieron forzados a abandonar sus misiones y recurrir a préstamos que no les era posible pagar. ${ }^{13}$

Pese a todo, el Colegio de Guadalupe logró sobrevivir a la primera mitad del siglo xIX ostentando aún cierto prestigio y riqueza. Hacia finales de la década de 1850, seguía siendo uno de los conventos más poblados del país. Albergaba a 116 individuos, 79 de ellos frailes, 19 donados, 4 novicios y el resto civiles. Para entonces en el país habitaban 1295 frailes de todas las órdenes, repartidos en 144 conventos. ${ }^{14}$ De estos frailes, 252 se hallaban en los seis colegios de Propaganda Fide del país. De tal modo, tan sólo el Colegio de Guadalupe albergaba a 6\% de los frailes del país y a una tercera parte de los franciscanos de los colegios.

\section{EL TIRO DE GRACIA: EL LIBERALISMO ZACATECANO}

Y LA LEY DEL 12 DE JULIO DE 1859

Para la década de 1850, las críticas de los liberales contra la Iglesia mexicana se recrudecieron. Estos consideraron la vida conventual y el juramento de votos perpetuos como una restricción a la libertad individual, garantizada por la Constitución

12 Torre Curiel, Vicarios en entredicho, pp. 230-233.

13 Torre Curiel, Vicarios en entredicho, pp. 233-234; Torre Curiel y Ruiz Alcalá, “La provincia franciscana de Santiago Xalisco, 1824-1860”, pp. 85-95.

14 Bazant, Los bienes de la Iglesia, p. 8. 
de $1857 .{ }^{15}$ Hubo quienes pensaron que los frailes no eran más que fanáticos, supersticiosos, ociosos, de vidas holgadas y abusadores de la caridad pública. ${ }^{16}$ De igual manera, se creyó que las propiedades urbanas y rurales que poseían no estaban siendo explotadas al máximo y que las rentas que cobraban a sus labradores perjudicaban las finanzas de los que las trabajaban, afectando a fin de cuentas a la economía nacional. ${ }^{17}$ Algunos liberales opinaron que los claustros eran edificios inútiles, sobre los cuales se debían levantar espacios provechosos para la sociedad, como escuelas, plazas, talleres u hospicios..$^{18}$ Fue en ese contexto que, el 25 de junio de 1856, los liberales en el poder gracias a la revolución de Ayutla (1854-1855) promulgaron la ley de desamortización de bienes eclesiásticos. Esta obligó a todas las corporaciones civiles y religiosas a vender sus propiedades. Así mismo, tres años después, en plena Guerra de Reforma, radicalizaron aún más sus disposiciones. Si bien la oposición en el Congreso Constituyente de 1856 evitó que se legislara sobre la supresión de corporaciones religiosas y la libertad de culto, al presidente Benito Juárez y a su gabinete no les costó nada realizarlo en 1859, pues al iniciar la guerra le fueron concedidas facultades discrecionales al poder ejecutivo. Se pensó que, si se nacionalizaban los bienes de la Iglesia y se exclaustraba a los frailes, se evitaría que las órdenes invirtieran en la causa conservadora, como estaba ocurriendo, pero además se conseguirían recursos rematando sus propiedades. ${ }^{19}$ Fue en ese sentido que se promulgó la ley del 12 de julio de 1859.

15 Bautista García, Las disyuntivas del Estado y de la Iglesia, pp. 283-284; Connaughton, "De la tensión de compromiso", pp. 99-100.

16 Covo, Las ideas de la Reforma en México, pp. 523-524.

17 MariÑo Jaso, "Desamortización de bienes corporativos", pp. 88-91; BAZANT, Los bienes de la Iglesia, p. 12.

18 "Votos monásticos", El Movimiento, 58 (4 mar. 1861), p. 1.

19 Covo, Las ideas de la Reforma, p. 520. 
La ley del 12 de julio de 1859 fue publicada en Veracruz. Se justificó alegando que el clero mexicano, en "abierta rebelión" contra el "gobierno soberano", había sido "una de las rémoras constantes para establecer la paz pública". Su artículo primero ordenó la nacionalización de todos los bienes del clero secular y regular, ya que éste se había resistido a vender la mayor parte de ellos tras la promulgación de la ley de desamortización. Así mismo, su quinto artículo estipuló la supresión de las órdenes masculinas del país. La ley prohibía, además, la fundación de nuevos conventos y noviciados, el uso de hábitos, y "reducía" a todos los frailes al clero diocesano. Todo fraile que cooperara sería beneficiado con 500 pesos. A los frailes enfermos y ancianos que no pudieran continuar ejerciendo su ministerio se les ayudaría con otros 3000 . En cambio, todo aquel que al cabo de 15 días de publicada la ley en su distrito continuara vistiendo hábito y viviendo en comunidad, no recibiría ninguna ayuda y sería expulsado inmediatamente del país. ${ }^{20}$

Con anterioridad, algunos estados ya habían tomado providencias similares contra los religiosos y sus bienes. Zacatecas fue uno de ellos. Su gobernador, el general Jesús González Ortega, publicó dos leyes con objetivos similares en los momentos más álgidos de la Guerra de Reforma. Hacia mediados de 1859, la contienda se recrudeció en el estado, librándose sin garantías y con extrema violencia, pero sin que la balanza de la victoria se inclinara hacia ningún partido. ${ }^{21} \mathrm{El}$ clero regular y secular del estado actuaba abiertamente en pro de los conservadores. Los sacerdotes promulgaban sermones a su favor y los ayudaban económicamente. Fue en ese tenor que González Ortega decretó una ley penal el 12 de junio de 1859 y, como consecuencia, otra de nacionalización el 15 de julio.

20 "Julio 12 de 1859. Ley de nacionalización de los bienes eclesiásticos", en Tena Ramírez (comp.), Leyes fundamentales de México, pp. 638-641.

21 Galindo y Galindo, La gran década nacional, pp. 128-197; VALdÉs, Memorias de la Guerra de Reforma, pp. 187-193. 
La ley penal del 12 de junio del estado de Zacatecas, también llamada ley de "conspiradores", condenó a muerte a todo religioso que respaldara la causa conservadora. ${ }^{22}$ Con motivo de su promulgación, casi todos los sacerdotes de Zacatecas salieron del estado y muchos de los frailes abandonaron sus conventos en secreto. Sólo cinco sacerdotes diocesanos permanecieron en Zacatecas, todos partidarios de la causa liberal, llamados “apóstatas" por otros clérigos. ${ }^{23}$ Los frailes de Guadalupe tampoco desocuparon su convento. Aunque algunos vecinos lo recomendaron, prefirieron no hacerlo, considerando que la situación sería pasajera. ${ }^{24}$ Por su parte, la diócesis de Guadalajara, de la que dependía el clero zacatecano, motivó la salida de los religiosos y criticó a quienes no la efectuaron. ${ }^{25}$ Con ello, el obispo procuró darles a los habitantes del estado un motivo para repudiar las decisiones del gobierno liberal como estrategia política. En respuesta a la evacuación y al creciente descontento de los zacatecanos, González Ortega fomentó el ingreso de sacerdotes

22 "Junio 16 de 1859. Decreto del gobierno de Zacatecas sobre ley de conspiradores y sus cómplices”, AGN, JA, vol. 612, exp. 1; Espinosa y DÁvalos, Carta pastoral, pp. 7-13.

${ }^{23}$ Carta de fray Diego de la Concepción Palomar a Pedro Espinosa en Guadalajara; Zacatecas, 4 de agosto de 1859, BNAH, RIIM, c. 1, doc. 198; "Conducta de Fr. Diego de la C. Palomar", AHFZ, CAG, Correspondencia de fray Diego de la Concepción Palomar, vol. I, pp. 1-5; VIDAL, Continuación del bosquejo histórico de Zacatecas, pp. 48-49, 51; SотомаYOR, Historia del apostólico Colegio, p. 294.

${ }^{24}$ Cuando se tuvo noticia de la publicación de la ley penal y de todo lo que estaba causando, el guardián del Colegio de Guadalupe (fray Diego de la Concepción Palomar) mandó reunir a su comunidad el 19 de junio. Dándoles un discurso, invitó a salir del estado a quien quisiese, lo cual no fue de la voluntad de nadie. "Conducta de Fr. Diego de la C. Palomar", AHFZ, CAG, Correspondencia de fray Diego de la Concepción Palomar, vol. I, pp. 1-3; Sotomayor, Historia del apostólico Colegio, p. 295.

${ }^{25}$ Gobierno eclesiástico de Guadalajara a fray José María Romo en Guadalupe; Guadalajara, 9 de agosto de 1859, BNAH, RIIM, c. 1, doc. 202; EsPINOsA y Dávalos, Carta pastoral; SÁnchez TAgLe, ;Muera el ejército!, pp. 218-219. 
estadounidenses. ${ }^{26}$ Además, publicó la citada ley del 15 de julio de 1859, con la cual ordenó que todo convento abandonado en Zacatecas pasara a manos del gobierno del estado, así como sus fincas y propiedades. ${ }^{27}$

De este modo, la nacionalización y exclaustración de regulares se anticipó en Zacatecas. La ley federal del 12 de julio no llegó a oídos de González Ortega sino hasta el 29 de julio de 1859, por conducto extraordinario de San Luis Potosí, donde ya se había aplicado. Dicha ley coincidió y respaldó mucho de lo que su gobierno ya había comenzado. Fue dada a conocer en el estado el 31 de julio de 1859, aunque los rumores de su existencia ya habían circulado bastante. Fue por ello que, con antelación, algunos vecinos influyentes de Guadalupe, como Juan Arteaga, José María Ávila, José González y Echeverría y Miguel González (cónsul español), se presentaron ante González Ortega para solicitar que pidiese a Juárez que el Colegio quedara eximido de la ley. Al tiempo, se presentó una comisión de religiosos de Guadalupe solicitando lo mismo. Según Francisco Marentes, sacerdote secular que residía en la villa de Guadalupe, González Ortega se negó a retrasar la publicación del decreto, pero en cambio les dijo que "no tuvieran cuidado", pues si recaudaban suficientes firmas intercedería ante Juárez..$^{28}$

El 31 de julio, tras haber sido publicada la ley de nacionalización, comenzó a rumorearse que la villa de Guadalupe se amotinaría. Luego de que sus vecinos se enteraron del decreto,

26 "Conducta de Fr. Diego de la C. Palomar", AHFZ, CAG, Correspondencia de fray Diego de la Concepción Palomar, vol. I, p. 9v.; SÁnChez Tagle, ¡Muera el ejército!, p. 219.

27 "Decreto de Jesús González Ortega, Zacatecas, 15 de julio de 1859", BNAH, RIIM, c. 1, doc. 194, f. 1; “Zacatecas”, en Diario Oficial del Supremo Gobierno, 495 (8 ago. 1859), p. 1.

${ }^{28}$ Francisco Marentes a Pedro Espinosa, obispo de Guadalajara, en Guadalajara; Zacatecas, 2 de agosto de 1859, BNAH, RIIM, 1, doc. 197; "Conducta de Fr. Diego de la C. Palomar”, AHFZ, CAG, Correspondencia de fray Diego de la Concepción Palomar, vol. I, p. 6. 
una multitud, preocupada, se introdujo en el Colegio. El gentío inundó el pórtico, el claustro, los patios y la huerta. Algunos pidieron hablar con el guardián, fray Diego de la Concepción Palomar, solicitando consejo para pronunciarse. Otros fueron a confesarse y a comulgar, según Marentes, "para [poder] morir en defensa de sus herencias”. Cuando se retiraron, todo pareció volver a la calma. Sin embargo, alarmado, Francisco Delgado, presidente municipal de Guadalupe, solicitó a la jefatura política de Zacatecas una tropa de 100 hombres "para hacerse respetar”. En la noche estalló un motín bastante concurrido al grito de “iViva la Religión, viva la Virgen de Guadalupe, mueran los infieles!”. Los pronunciados esperaban que en la ciudad de Zacatecas ocurriera algo similar. La corta guarnición de la villa, compuesta por nueve hombres, no pudo pacificar a la población, de manera que tuvieron que recurrir a González Ortega, quien despachó de inmediato una fuerte columna. Esta dio fin al levantamiento. Dos civiles resultaron muertos, se hicieron varios prisioneros y a la mañana siguiente se fusiló a uno de ellos, Marcelo Moreno, criado del convento. Su cadáver fue colgado frente a la puerta del Colegio. González Ortega aseguró que buscaría y ajusticiaría a los demás instigadores. ${ }^{29}$

Los religiosos y los partidarios del Colegio que escribieron al respecto afirmaron que los frailes de Guadalupe no tuvieron

${ }^{29}$ Francisco Delgado al jefe político de Zacatecas; Guadalupe, 30 de julio de 1859, AHEZ, JPZ, Correspondencia con las municipalidades, Guadalupe, c. 5, s/f.; Francisco Delgado al jefe político de Zacatecas; Guadalupe, 2 de agosto de 1859, AHEZ, JPZ, Correspondencia con las municipalidades, Guadalupe, c. 5, s/f.; Jesús González Ortega a Benito Juárez en Veracruz; Zacatecas, 1ํ de agosto de 1859, AGN, J, vol. 626, exp. 2, ff. 5-6; Francisco Marentes a Pedro Espinosa, obispo de Guadalajara, en Guadalajara; Zacatecas, 2 de agosto de 1859, BNAH, RIIM, c. 1, doc. 197; “Conducta de Fr. Diego de la C. Palomar”, AHFZ, CAG, Correspondencia de fray Diego de la Concepción Palomar, vol. I, pp. 7-9; SotomaYor, Historia del apostólico Colegio, pp. 298-299; VIDAL, Continuación del bosquejo histórico, t. I, p. 51; TisCAREÑo, El Colegio de Guadalupe, t. III, p. 513. 
nada que ver con el motín y que incluso intentaron disuadir a los que lo promovieron. Fray Tiscareño llegó un poco más lejos. Aseguró que fue el mismo González Ortega quien promovió en secreto el pronunciamiento con sus agentes, como excusa para exclaustrar a la comunidad y no tener que solicitar a Juárez lo que había prometido. ${ }^{30}$ González Ortega, por el contrario, aseguró en una carta enviada al presidente que todo había sido culpa del vecindario. "Era natural que el pueblo bajo de aquella villa, ignorante y fanático, lleno de ideas supersticiosas, intentara oponerse a la exclaustración de aquella comunidad". En su respuesta, Juárez aplaudió sus diligencias y le sugirió seguir "aplicando el rigor de las leyes". ${ }^{31}$

Para entonces, la villa de Guadalupe contaba con cerca de 4000 habitantes y, según un panfleto conservador, estaba profundamente influenciada por el convento, pues gran parte de su vida giraba en torno a él..$^{32} \mathrm{Tal}$ afirmación puede no estar muy lejos de la realidad. Con anterioridad, los habitantes de Guadalupe ya se habían mostrado en contra de ciertas disposiciones liberales. El 14 de julio de 1856, por ejemplo, la población se amotinó en contra de la ley de desamortización, como resultado del sermón de un fraile. En consecuencia, 11 hombres fueron aprehendidos y se advirtió al guardián del convento que "cuide

\footnotetext{
30 Francisco Marentes a Pedro Espinosa, obispo de Guadalajara, en Guadalajara; Zacatecas, 2 de agosto de 1859, BNAH, RIIM, c. 1, doc. 197; "Conducta de Fr. Diego de la C. Palomar", AHFZ, CAG, Correspondencia de fray Diego de la Concepción Palomar, vol. I, pp. 7-8; SOTOMAYOR, Historia del apostólico Colegio, pp. 298-299; VIDAL, Continuación del bosquejo histórico, tomo I, p. 51; Tiscareño, El Colegio de Guadalupe, t. III, p. 513.

${ }^{31}$ Jesús González Ortega a Benito Juárez en Veracruz; Zacatecas, 1ํo de agosto de 1859, AGN, Jus, vol. 626, exp. 2, ff. 5-6; Manuel Ruiz, Ministro de Justicia, a Jesús González Ortega en Zacatecas; Veracruz, 25 de agosto de 1859, AGN, J, vol. 626, exp. 2, f. 6 .

32 Crímenes de la demagogia, pp. 5-6.
} 


\section{Imagen 2}

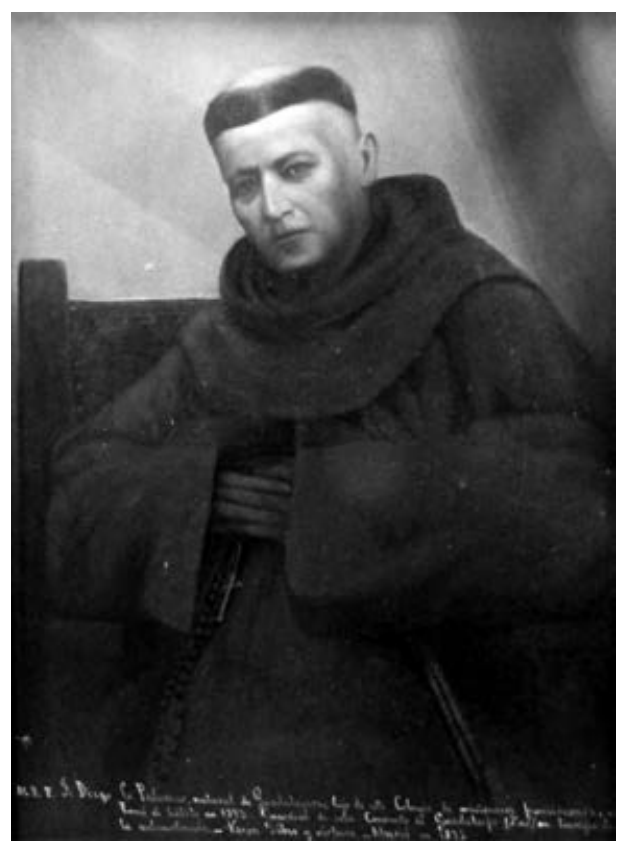

Fray Diego de la Concepción Palomar. Guardián de la comunidad de Guadalupe durante la exclaustración. FuENTE: CMG.

[...] que sus religiosos no abusen del púlpito". ${ }^{33}$ Así mismo, cuando fue promulgada la Constitución de 1857 y se obligó a todos los funcionarios públicos a jurarla bajo pena de despido, en Guadalupe cinco regidores y el síndico del ayuntamiento se negaron a hacerlo y renunciaron. Esto no ocurrió en otras localidades del estado, o al menos no a tal grado. En la ciudad de Zacatecas, por ejemplo, sólo fueron dos regidores los que pidieron su renuncia. Años más tarde, en 1886, parte del vecindario

33 Amador, Bosquejo histórico de Zacatecas, t. II, pp. 538-539; SáncheZ TAGLE, ;Muera el ejército!', p. 59. 
se mostró sumamente hostil al culto evangélico y dos años después, cerca de 200 individuos se quejaron del insulto que el periódico La Voz del Siglo hizo a la Virgen de Guadalupe. ${ }^{34}$

El motín del 31 de julio de 1859 trajo consecuencias drásticas para el Colegio. A pesar de lo estipulado por la ley, González Ortega no le concedió 15 días a la comunidad para que se exclaustrara, sino 24 horas. La noticia fue recibida por los religiosos a la mañana siguiente. Sin éxito, el guardián envió a González Ortega una comisión para rogarle que cambiara de parecer. Sólo les permitió dejar un fraile "para continuar el culto y cuidar los intereses de la casa". ${ }^{35}$ Fue entonces cuando el guardián del Colegio, fray Diego Palomar, mandó reunir a toda su comunidad. Exhortó a los frailes a que siguieran cumpliendo "los deberes contraídos ante Dios mediante la profesión religiosa, [...] no obstante la azarosa situación" en la que se hallaban. Sin embargo, también les recordó que eran libres de tomar el rumbo que quisieran y de continuar vistiendo o no el hábito. Luego de ello, los 116 religiosos, novicios y civiles de Guadalupe comenzaron a abandonar el Colegio, vigilados por una guarnición. Antes de salir, la comunidad pasó a la iglesia, en donde, entre sollozos, algunos frailes renovaros sus votos mientras que otros rezaron. ${ }^{36}$

${ }^{34}$ Secretaría del gobierno del estado de Zacatecas al presidente municipal de Guadalupe; Zacatecas, 31 de mayo de 1886, AHEZ, JPZ, Correspondencia con las municipalidades, Guadalupe, c. 5, s/f.; SÁNchez TAGLE, ;Muera el ejército!, pp. 40, 53; La Voz del Siglo, 22 (4 jul. 1888); "Suplemento al número 22 de $L a$ Voz del Siglo” (13 jul. 1888), AHEZ, JPZ, Correspondencia general, Asuntos eclesiásticos, c. 1, exp. 2.

${ }^{35}$ Fray Diego de la Concepción Palomar a Pedro Espinosa en Guadalajara; Zacatecas, 4 de agosto de 1859, BNAH, RIIM, c. 1, doc. 198.

${ }^{36}$ Las censuras de los conservadores y de parte de la sociedad por la exclaustración de la comunidad guadalupana no se dejaron esperar. En cuestión de días salieron a la luz libelos, panfletos y artículos periodísticos que condenaban severamente la conducta de los liberales y se lamentaban por todo lo que pasaron los religiosos. La mayoría exageraba los hechos al asegurar, por ejemplo, que todo aquel que se mostraba afligido por el hecho era fusilado. A juzgar por la cantidad de escritos publicados, de todo el país, fue tal vez la exclaustración 
La exclaustración no significó la desaparición de la congregación, como la ley del 12 de julio estipulaba, sino una nueva etapa para ella. Si bien algunos religiosos la fueron abandonando conforme pasaba el tiempo, el resto consiguió mantenerla viva adoptando ciertas estrategias, corriendo los riesgos de la guerra y desobedeciendo las leyes civiles. Una vez exclaustrados, muchos religiosos no supieron qué hacer, pues habían pasado toda su vida en el convento. La mayor parte de la comunidad deseó permanecer unida, razón por la cual casi todos acataron la sugerencia de fray Diego Palomar, quien marchó a "recogerse" al Colegio de Querétaro, aún bajo el amparo conservador. ${ }^{37}$ Algunas familias, como los Fagoaga, los Llaguno, los Pereda y los Gordoa, ayudaron a los exclaustrados en su

a la que mayor cobertura se dio. Incluso al mes siguiente, el 1o de septiembre de 1859, cuando una aurora boreal alcanzó a verse desde Guadalajara (algo que desde el siglo pasado no había ocurrido por ser sumamente raras en regiones tan próximas al ecuador), los vecinos de la ciudad, al verla desde el norte, pensaron que Zacatecas había sido consumida por fuego celeste como castigo por la exclaustración de Guadalupe en específico, mas no por la de otras comunidades del mismo estado. Crímenes de la demagogia; "La demagogia en Zacatecas. Clausura del Colegio Apostólico de Guadalupe y la expulsión de los religiosos", La Sociedad, 591 (16 ago. 1859), p. 1; "Religiosos”, La Sociedad, 594 (19 ago. 1859), p. 3; "Los religiosos de Guadalupe”, La Sociedad, 595 (20 ago. 1859), p. 3; "Escándalos de la demagogia en Zacatecas", La Sociedad, 600 (25 ago. 1859), p. 3; "El Colegio Apostólico de Guadalupe", La Sociedad, 604 (29 ago. 1859), p. 3; "Los religiosos del Colegio Apostólico de Zacatecas", La Sociedad, 611 (5 sept. 1859), p. 2; "El colegio de Guadalupe de Zacatecas", La Sociedad, 750 (22 ene. 1860), p. 1; "Zacatecas”, Diario Oficial del Supremo Gobierno, 504 (17 ago. 1859), p. 2; "Religiosos", Diario Oficial del Suspremo Gobierno, 507 (20 ago. 1859), p. 3; "Los religiosos de Guadalupe", Diario Oficial del Supremo Gobierno, 508 (21 ago. 1859), p. 3; CAMBre, La Guerra de Tres Años, p. 289; Pérez Verdía, Luis, Historia particular del Estado de Jalisco, t. III, p. 75.

37 Fray Diego Palomar partió al Colegio de Querétaro porque sabía que el de Zapopan, aunque se hallaba más cerca, no tenía espacio para hospedar "ni 
salida, proporcionándoles carruajes, caballos, mulas, mozos y toda suerte de géneros. Fray Palomar fue de los primeros en abandonar la villa. Como muchos otros, no colgó el hábito, pero se cubrió con manto y sombrero. Antes de partir, se dirigió a Zacatecas a caballo para arreglar ciertos asuntos y escribir a la mitra de Guadalajara, encabezada por el obispo Pedro Espinosa, a la cual, según la ley del 12 de julio, debía obedecer. ${ }^{38}$

Luego de lamentarse frente al convento, la comunidad comenzó a disgregarse durante el transcurso de la tarde. Ya fuese a tracción animal o a pie, la mayor parte se encaminó a Querétaro en grupos de dos o tres. Casi todos salieron de Guadalupe sin más que su Breviario y tuvieron que recurrir a la caridad en su camino. Pese a que eran religiosos misioneros acostumbrados a recorrer largas distancias, no habían hecho ningún preparativo para el viaje. Algunos frailes pasaron a reunirse con sus familias. Otros, como Juan Crisóstomo Gómez, abandonaron el hábito de inmediato, alegando que con ello evitarían posibles reprimendas. ${ }^{39}$ Gracias a que fray Tiscareño rescató en su libro el testimonio de un fraile anónimo, sabemos a detalle la experiencia que vivieron algunos. Tras la exclaustración, dicho fraile fue invitado por fray Luis Zubía a viajar a Querétaro en los dos caballos que le prestó la familia Gordoa. En su camino fueron auxiliados por hacendados, pero también por gente humilde, quienes les ofrecieron hospedaje y alimentos según sus posibilidades. A lo largo de su trayecto, hallaron a otros grupos de frailes, novicios y civiles de su hermandad, los cuales

a diez religiosos" ("Conducta de Fr. Diego de la C. Palomar", AHFZ, CAG, Correspondencia de fray Diego de la Concepción Palomar, vol. I, p. 7.

38 "Conducta de Fr. Diego de la C. Palomar", AHFZ, CAG, Correspondencia de fray Diego de la Concepción Palomar, vol. I, pp. 8-13; Tiscareño, El Colegio de Guadalupe, t. IV, p. 19; Carta de fray Diego de la Concepción Palomar a Pedro Espinosa en Guadalajara; Zacatecas, 4 de agosto de 1859, BNAH, RIIM, c. 1, doc. 198.

39 Sotomayor, Historia del apostólico Colegio, pp. 276, 311; Tiscareño, El Colegio de Guadalupe, t. IV, p. 15. 
se les unieron. En Lagos de Moreno fueron acogidos en casa de fray Alonso Orozco, perteneciente a una rica familia que auxiliaba a la comunidad. No pudieron permanecer más de tres días en aquella población, pues la columna liberal de Silvestre Aranda se aproximaba. Para continuar su camino, les fueron proporcionadas algunas carrozas. En el trayecto pasaron por campamentos militares conservadores ${ }^{40}$ y liberales. De no haber reconocido uno de los jefes liberales a fray Zubía, tal vez su grupo no hubiera podido continuar su camino sin alguna vejación. Sólo por eso fueron recibidos cortésmente y, tras ofrecerles que se unieran a su fuerza y de prometerles una vida feliz "en compañía de algunas hermosas fronterizas”, se les permitió continuar. Hasta el 14 de agosto, luego de dos semanas de viaje, llegaron a Querétaro. ${ }^{41}$ El guardián fray Diego Palomar, por su parte, viajó todo el tiempo en carruaje, hospedándose en haciendas y casonas de vecinos acaudalados. ${ }^{42}$

Pero no todos los frailes tuvieron un buen trayecto. Dos que iban a caballo fueron interceptados por una patrulla de soldados liberales, los cuales los insultaron, desmontaron y los obligaron a quitarse el hábito. ${ }^{43}$ En todo el país circulaban destacamentos con órdenes terminantes de Santos Degollado para que aplicaran la ley del 12 de julio de manera inflexible. Cuando el coronel Manuel Valdés tuvo noticia de esta disposición, mandó celebrarla con júbilo en su campamento. "Esta era la medida

${ }^{40}$ Los militares conservadores solían comportarse de manera condescendiente con todo fraile exclaustrado. Cuando Leonardo Márquez se enteró de los hechos de Guadalupe se escandalizó. Ofreció acoger a todo religioso que llegara a Guadalajara. García Ugarte, Poder político y religioso, t. I, p. 838; "Los religiosos del Colegio Apostólico de Zacatecas", La Sociedad, 611 (5 sept. 1859), p. 2.

${ }^{41}$ Tiscareño, El Colegio de Guadalupe, t. IV, pp. 20-30.

42 "Conducta de Fr. Diego de la C. Palomar", AHFZ, CAG, Correspondencia de fray Diego de la Concepción Palomar, vol. I, pp. 13-21.

${ }^{43}$ Carta de fray M. M. M. de P. a fray Miguel Macías Valdés en Guadalajara; Plateros, 14 de agosto de 1859, BNAH, RIIM, c. 1, doc. 203, f. 1. 
-aseguró- que exigía la salvación de México" ${ }^{44}$ A pesar de eso, muchos de los que eran despojados de su hábito lo volvían a vestir cuando dejaban de estar en peligro. ${ }^{45}$ Durante la primera mitad de 1860, cuando fray Diego Palomar, acompañado de 20 religiosos, visitó el Colegio de Pachuca, fue capturado por el general Antonio Carvajal al ocupar la plaza. Carvajal lo tomó preso junto con fray Modesto Escárcega, guardián del Colegio de Pachuca, y los obligó a quitarse el hábito y vestir pantalón, frazada y zapatos. Su rescate fue pagado con 1500 pesos. Una vez que fray Palomar pudo regresar a la Ciudad de México, volvió a usar hábito y ordenó a su comunidad que saliera de Pachuca de inmediato. ${ }^{46}$

A pesar de que la mayor parte de la comunidad fue a "recogerse" al Colegio de la Santa Cruz de Querétaro, no toda se mantuvo unida. Varios hermanos se diseminaron por diversos rumbos. Cuatro de los frailes permanecieron en sus misiones en Nayarit, otros cinco fueron a recogerse al Colegio de San Fernando de la Ciudad de México, dos a Durango y "algunos religiosos" pasaron a residir a ciertos puntos de Jalisco, particularmente Guadalajara y al Colegio de Zapopan. Fray Guadalupe de Jesús González, por ejemplo, regresó con sus padres a la Hacienda del Comedero, Jalisco, sin colgar el hábito. ${ }^{47}$ Un par

${ }^{44}$ Valdés, Memorias de la Guerra de Reforma, pp. 168-169.

${ }^{45}$ Gobierno eclesiástico de Guadalajara a fray Miguel de Guzmán s/l; Guadalajara, 31 de agosto de 1859, BNAH, RIIM, c. 2, doc. 212.

46 "Conducta de Fr. Diego de la C. Palomar", AHFZ, CAG, Correspondencia de fray Diego de la Concepción Palomar, vol. I, pp. 28-29, 31-38; TisCAREÑo, El Colegio de Guadalupe, t. IV, pp. 35-36.

${ }^{47}$ Fray Guadalupe de Jesús González a Pedro Espinosa en Guadalajara; Hacienda del Comedero, 14 de agosto de 1859, BNAH, RIIM, c. 2, doc. 205; fray José María Sánchez Álvarez a fray Diego de la Concepción Palomar en Querétaro; Guadalajara, 29 de octubre de 1859, AHFZ, CAG, Correspondencia de fray Diego de la Concepción Palomar, vol. I, s/ff.; "Conducta de Fr. Diego de la C. Palomar", AHFZ, CAG, Correspondencia de fray Diego de la Concepción Palomar, vol. I, pp. 22-23, 25; Tiscareño, El Colegio de Guadalupe, t. IV, p. 30. 
de religiosos "locos" fueron dejados en Guadalupe a cargo del presbítero Marentes. ${ }^{48}$ Otro caso interesante fue el del fraile guadalupano que tenía encomendado el santuario del Santo Niño de Atocha en Plateros. Dicho fraile, que firmaba como M. M. M. de P., decía tener 74 años y estar bastante enfermo. Cuando recibió la noticia de la exclaustración por parte del jefe político de Fresnillo, afirmó hallarse consternado y no saber qué hacer. De inmediato respondió a las autoridades que se sometería "enteramente a la obediencia" del obispo y que se desprendería del hábito. ${ }^{49} \mathrm{~A}$ los pocos días escribió a su sobrino que, por su condición, le resultaba imposible seguir a sus hermanos y que, para prevenir cualquier abuso, se hallaba envuelto en un capuchón que él mismo fabricó. Sólo usaba el hábito dentro de su casa y cuando su enfermedad no le permitía quitárselo. Para no infringir cualquier norma eclesiástica, solicitó al obispo de Guadalajara que le permitiera vestir sotana clerical y administrar penitencia..$^{50} \mathrm{~A}$ juzgar por los registros del Archivo General de la Nación, jurar obediencia a la ley de nacionalización no fue una práctica común. Según el archivo del Ministerio de Justicia, en los años de 1859 y 1860, sólo tres frailes lo hicieron, todos franciscanos, y no por los 500 pesos que les ofrecían, pues los rechazaron..$^{51}$

${ }^{48}$ Francisco Marentes a Pedro Espinosa, obispo de Guadalajara, en Guadalajara; Zacatecas, 2 de agosto de 1859, BNAH, RIIM, c. 1, doc. 197.

${ }^{49}$ Fray M. M. M. de P. al jefe político de Fresnillo; Plateros, 9 de agosto de 1859, BNAH, RIIM, c. 1, doc. 200.

${ }^{50}$ Fray M. M. M. de P. a fray Miguel Macías Valdés en Guadalajara; Plateros, 14 de agosto de 1859, BNAH, RIIM, c. 1, doc. 200.

51 Manuel Gutiérrez Zamora, gobernador de Veracruz, a Manuel Ruiz, Ministro de Justicia, en Veracruz; Veracruz, 5 de septiembre de 1860, AGN, $J$, vol. 612, exp. 1, ff. 2-2v.; fray Juan Zambrano a Manuel Ruiz en Veracruz; Orizaba, 22 de octubre de 1860, AGN, J, vol. 612, exp. 1, ff. 16-16v.; "Índice de los expedientes que remite el Ministro de Justicia al Ministro de Relaciones Exteriores y Gobernación. Años de 1859-1861”, en AGN, J, vol. 645, exp. 121, ff. 312-324v. 
Otros cuatro guadalupanos tampoco siguieron a la comunidad. Luego de la exclaustración, por disposición de González Ortega, se les permitió permanecer en la villa para cuidar la iglesia del convento y el culto, viviendo fuera del claustro y vestidos con sotana. Aunque podían oficiar misa, no tenían autorización de administrar sacramentos, cosa que solicitaron al obispo de Guadalajara. Así mismo, fray Palomar pidió permiso a la mitra para que el resto de la comunidad en su camino a Querétaro pudiera oficiar misas y dar sacramentos..$^{52}$ La respuesta de la diócesis a los frailes fue inesperada. Para entonces el obispo se hallaba ausente, de manera que les contestó el cabildo eclesiástico. En sus cartas, el cabildo lamentó lo que les estaba pasando a los religiosos. Sin embargo, les prohibió rotundamente abandonar el hábito, oficiar misas y administrar sacramentos. También les prohibió permanecer en Zacatecas o en otro territorio ocupado por los liberales, de manera que los cuatro frailes que quedaban en Guadalupe tuvieron que salir de inmediato. De no hacerlo, advirtió la mitra, pecarían de "apostasía", ${ }^{53}$ pues estarían contrariando sus votos, desobedeciendo las leyes eclesiásticas y -a fin

52 Tras la exclaustración, Jesús González Ortega le solicitó a fray Diego Palomar que distribuyera a su comunidad en todas las poblaciones del estado para que tomara el lugar del clero secular que la diócesis de Guadalajara ordenó evacuar. Fray Palomar se negó a ello, alegando que no contaba con la autorización, que los frailes no podían administrar todos los sacramentos y que para entonces la mayoría ya se hallaba fuera de Zacatecas. "Conducta de Fr. Diego de la C. Palomar", AHFZ, CAG, Correspondencia de fray Diego de la Concepción Palomar, vol. I, p. 10.

Fray Diego de la Concepción Palomar a Pedro Espinosa en Guadalajara; Zacatecas, 4 de agosto de 1859, BNAH, RIIM, c. 1, doc. 198, ff. 1-2v.; fray José María Romo a Pedro Espinosa en Guadalajara; Guadalupe, 9 de agosto de 1859, BNAH, RIIM, c. 1, doc. 199, ff. 1-2; fray Miguel Macías Valdés a la mitra de Guadalajara; Guadalajara, 21 de septiembre de 1859, BNAH, RIIM, c. 2, doc. 208, f. 1; "Conducta de Fr. Diego de la C. Palomar", AHFZ, CAG, Correspondencia de fray Diego de la Concepción Palomar, vol. I, p. 11.

${ }^{53}$ Es decir, la deserción ilegítima que causa un religioso al abandonar su orden. Dentro del derecho eclesiástico era considerado un pecado sumamente grave. 
de cuentas- sirviendo al gobierno liberal.${ }^{54}$ Con ello, el gobierno eclesiástico de Guadalajara tuvo como objetivo reforzar su estrategia de dejar Zacatecas sin clérigos. A todos los demás frailes que habían salido del estado, entre ellos el citado fray Guadalupe de Jesús González, que vivía con sus padres en su hacienda, tan sólo les permitió confesar y predicar, pero mientras estuviesen en territorios controlados por conservadores. ${ }^{55}$

Pese a todo, al dar órdenes a los religiosos, la mitra era la que propiciaba que los frailes pecaran de apostasía. Esto debido a que, al hacerlo, acataba la ley del 12 de julio, en su artículo que indicaba que todas las órdenes quedaban "reducidas" al clero secular. Además, la diócesis incurría en una falta grave al imponerse sobre los derechos y exenciones canónicas de los regulares. Esto, sin embargo, no detuvo al cabildo en esas decisiones. Tampoco hubo resistencia por parte de los frailes, sino todo lo contrario. Esto le resultó bastante conveniente a la mitra, pues pudo hacer uso político de ellos en contra de los liberales y, de paso, apropiarse de sus bienes. Según el derecho canónico, los frailes exclaustrados podían seguir acatando a su comisario provincial, mientras que sus bienes debían quedar a cargo del síndico del convento y de un representante de la

${ }^{54}$ Gobierno eclesiástico de Guadalajara a fray José María Romo en Guadalupe; Guadalajara, 11 de agosto de 1859, BNAH, RIIM, c. 1, doc. 202; Gobierno eclesiástico de Guadalajara a Francisco Marentes en Guadalupe; Guadalajara, 13 de agosto de 1859, BNAH, RIIM, c. 1, doc. 204; Gobierno eclesiástico de Guadalajara a fray Felipe de Jesús en Zacatecas; Guadalajara, 29 de agosto de 1859, BNAH, RIIM, c. 2, doc. 211; Gobierno eclesiástico de Guadalajara a fray Miguel de Guzmán s/l; Guadalajara, 31 de agosto de 1859, BNAH, RIIM, c. 2, doc. 212; "Conducta de Fr. Diego de la C. Palomar", AHFZ, $C A G$, Correspondencia de fray Diego de la Concepción Palomar, vol. I, pp. 17-20; Gobierno eclesiástico de Guadalajara, Manifestación que bace el gobierno eclesiástico de Guadalajara.

${ }^{55}$ Gobierno eclesiástico de Guadalajara a fray Guadalupe de Jesús González en la hacienda del Comedero; Guadalajara, 20 de agosto de 1859, BNAH, RIIM, c. 2, doc. 206; “Conducta de Fr. Diego de la C. Palomar”, AHFZ, CAG, Correspondencia de fray Diego de la Concepción Palomar, vol. I, pp. 29-31. 
Santa Sede, en este caso, Alejandro del Hoyo. De acuerdo con las leyes eclesiásticas, la Santa Sede era la única que tenía derecho sobre todas las pertenencias de los religiosos que hacían voto de pobreza. ${ }^{56}$ Así, cualquier otra instancia que pretendiera sus bienes, fuera el gobierno o alguna diócesis, violaba sus derechos. ${ }^{57}$ En sus cartas al gobierno eclesiástico de Guadalajara, los frailes parecen no tomar en cuenta que obedecer las órdenes de la mitra los convertía en apóstatas. Al mismo tiempo, algunos alegaron que, aunque tuvieron que dejar el hábito, eso no los extraía de la orden ni de la obediencia y obligaciones que tenían con ella. Pensaron que, al tener que hacerlo y dejar también el claustro, no estaban violando ninguna regla canónica, toda vez que lo hacían por la fuerza..$^{58}$ Pese a ello, la comunidad siguió atendiendo las disposiciones de la mitra. Esto pudo haberse debido, tal vez, a que se trataba de la instancia más cercana con facultades para auxiliarlos, como había ocurrido en el extranjero. En la Francia revolucionaria, por ejemplo, los obispos fueron los únicos que acogieron a las comunidades religiosas tras la exclaustración,

\footnotetext{
${ }^{56}$ Algunos años atrás, la Santa Sede y la Iglesia mexicana comenzaron a mostrar un claro interés por los bienes de las órdenes regulares. Esto con el propósito de reafirmar su autoridad sobre ellas y su autonomía frente al Estado. Durante la dictadura de Santa Anna, la Santa Sede consiguió evitar la desamortización de los bienes de las comunidades que el gobierno civil intentó hacer de manera "velada", según demostró Pablo Mijangos. Mujangos, Entre Dios y la República, pp. 223-236; Connaughton, "De la tensión de compromiso", p. 89.

57 Fray Diego de la Concepción Palomar a fray Joaquín María Morillos en Puebla; Guadalupe, 23 de diciembre de 1865, AHFZ, CAG, Correspondencia de fray Diego de la Concepción Palomar, vol. I, s/ff.; Tiscareño, El Colegio de Guadalupe, t. Iv, pp. 8-9.

${ }^{58}$ Fray Guadalupe de Jesús González a Pedro Espinosa en Guadalajara; Hacienda del Comedero, 14 de agosto de 1859, BNAH, RIIM, c. 2, doc. 205; fray M. M. M. de P. a fray Miguel Macías Valdés en Guadalajara; Plateros, 14 de agosto de 1859, BNAH, RIIM, c. 1, doc. 200; fray Diego de la Concepción Palomar al gobierno eclesiástico de Guadalajara; León, 23 de agosto de 1859, BNAH, RIIM, c. 2, doc. 210.
} 
a quienes ungieron como sacerdotes seculares. Algo similar ocurrió en España durante las décadas de 1830 y $1840 .{ }^{59}$

Por obediencia a la diócesis de Guadalajara, los cuatro religiosos que se quedaron en Guadalupe a cargo del templo se dirigieron a Querétaro a mediados de agosto de 1859. Entregaron las llaves del Colegio a ciertos vecinos para que se las dieran a la mitra o, si las exigía, al gobierno del estado. Fray Diego Palomar dio parte a su comunidad de la disposición de la diócesis de que todos debían abandonar Zacatecas y se disculpó con el cabildo eclesiástico por si en algo había cometido apostasía. ${ }^{60} \mathrm{La}$ mitra nombró un síndico para encargarse del Colegio, de su templo, de los vasos sagrados y de las alhajas. ${ }^{61}$ Luego de que la mayor parte de la comunidad se congregó en el Colegio de Querétaro, los religiosos pudieron reanudar su vida ritual. Sin embargo, debido a que las fuerzas liberales amenazaron la plaza, tuvieron que salir de ella a principios de noviembre de 1859 , junto con sus hermanos queretanos. Se dirigieron a pie a la Ciudad de México, con el propósito de recogerse en el Colegio de San Fernando, en donde también se hallaban refugiadas otras comunidades exclaustradas. Los religiosos de Guadalupe, reducidos para entonces a poco más de 80 personas según Tiscareño, se desplazaron en grupos de 10 y 12, llegando a San Fernando a lo largo de los

59 El problema de la conversión de frailes al clero secular en España fue, sin embargo, complicado, pues casi a ninguno de los secularizados se les dotó de parroquia. Muchos, entonces, acabaron en la indigencia y la mendicidad. Revuelta González, La exclaustración y Política religiosa de los liberales en el siglo XIX, pp. 331-332.

${ }^{60}$ Fray Diego de la Concepción Palomar al gobierno eclesiástico de Guadalajara; León, 23 de agosto de 1859, BNAH, RIIM, c. 2, doc. 210; "Conducta de Fr. Diego de la C. Palomar”, AHFZ, CAG, Correspondencia de fray Diego de la Concepción Palomar, vol. I, pp. 20-21.

${ }^{61}$ Gobierno eclesiástico de Guadalajara a Ambrosio Álvarez en Guadalupe; Guadalajara, 10 de agosto de 1859, BNAH, RIIM, c. 1, doc. 201; Ambrosio Álvarez al gobierno eclesiástico de Guadalajara; Guadalupe, 29 de agosto de 1859, BNAH, RIIM, c. 2, doc. 212. 
primeros días de diciembre. Una vez en la capital, engrosaron la gran población flotante que se había formado, compuesta en su mayoría por religiosos y familias refugiadas. Así mismo, fray Palomar asumió el cargo de comisario general de los colegios de Propaganda Fide del país, título que le fue concedido poco después de la exclaustración. Pese a ello, continuó obedeciendo las órdenes diocesanas. ${ }^{62}$

Ya en la Ciudad de México, fray Diego Palomar concibió la idea de crear un nuevo colegio en Puebla. Su formación ha sido vista hasta hoy como una fundación más; ${ }^{63}$ sin embargo, a juzgar por las circunstancias que la orden pasaba, lo más lógico es pensar que fue creado como otra estrategia de supervivencia de la comunidad y como desembarazo de frailes concentrados en el Colegio de San Fernando. Para su establecimiento, la Santa Sede autorizó utilizar el convento franciscano de San Gabriel de Cholula, el cual compartieron con los frailes que ya lo habitaban. La fundación fue llevada a cabo el 10 de agosto de 1860. El nuevo colegio fue instaurado bajo la advocación de la Inmaculada Concepción. Su comunidad la compusieron 23 hermanos, todos de Guadalupe, salvo por dos donados de San Fernando. ${ }^{64}$

Cuando durante los últimos meses de 1860 la guerra se inclinó drásticamente a favor de los liberales, la diócesis de Guadalajara cambió su estrategia en cuanto al uso de los frailes exclaustrados. Para noviembre, el gobierno conservador sólo poseía dos plazas de importancia, Ciudad de México y Puebla, en las cuales se

62 “Religiosos", La Sociedad, 594 (19 ago. 1859), p. 3; Tiscareño, El Colegio de Guadalupe, t. IV, pp. 34-35.

63 Esparza Sánchez, Compendio histórico del Colegio, pp. 135-137; Cázares Aguilar y Mejía Sánchez, "Notas para la historia del Colegio Apostólico de Propaganda Fide de Cholula”, pp. 299-312.

64 "Conducta de Fr. Diego de la C. Palomar", AHFZ, CAG, Correspondencia de fray Diego de la Concepción Palomar, vol. i, p. 31; Cázares Aguilar y Mejía SÁnchez, "Notas para la historia del Colegio Apostólico de Propaganda Fide de Cholula”, pp. 299-302; Tiscareño, El Colegio de Guadalupe, t. IV, pp. 34-35. 
había refugiado gran parte del clero regular del país. Casi todos los obispos también se hallaban en la Ciudad de México, Pedro Espinosa entre ellos. Así, agrupados durante dicho mes en un sínodo en la Profesa, redactaron unas "disposiciones" junto al arzobispo José Lázaro de la Garza y Ballesteros, tomando en cuenta la crítica situación en la que se encontraban los frailes. Adoptando una postura similar a la inicial de los religiosos de Guadalupe, los obispos y el arzobispo reconocieron que:

La ley de exclaustración no puede hacer que el religioso deje de serlo delante de Dios y de la Iglesia, ni rebajar en lo más mínimo la obligación que contrajo en su profesión por los votos solemnes que hizo, ni de las leyes y estatutos propios de su orden, los que deberán cumplir hasta donde les sea posible.

En ese sentido, el sínodo acordó que los frailes debían de seguir sometidos a sus propias autoridades y vestir el hábito en los lugares donde pudieran, como en sus casas o en templos. Para salir a la calle, por supuesto, debían evitarlo. Se les permitió vestir como el clero secular, pero con la condición de que bajo sus ropas portaran alguna prenda u objeto que honrara su voto de pobreza. Además, se les autorizó predicar y confesar y se dispuso que ningún fraile podía abandonar la diócesis a la que pertenecía su convento ni cambiar de residencia, y que si querían hacerlo debían pedir permiso. Pese a que no tenía la obligación, fray Diego Palomar se sometió a tales disposiciones. ${ }^{65}$

De todos los hermanos de Guadalupe, los que se hallaron en la peor situación fueron los novicios. Algunos de ellos estaban empeñados en "seguir la suerte de toda la comunidad", según afirmó el mismo Palomar. Si bien el gobierno civil y la diócesis permitieron a los frailes ejercer sacerdocio como clérigos

65 "Disposiciones a que han de sujetarse los religiosos si llegaren a ser exclaustrados", Ciudad de México, 12 de noviembre de 1860, AHAM, SA, Religiosos, c. 113 , exp. 50. 


\section{Imagen 3}

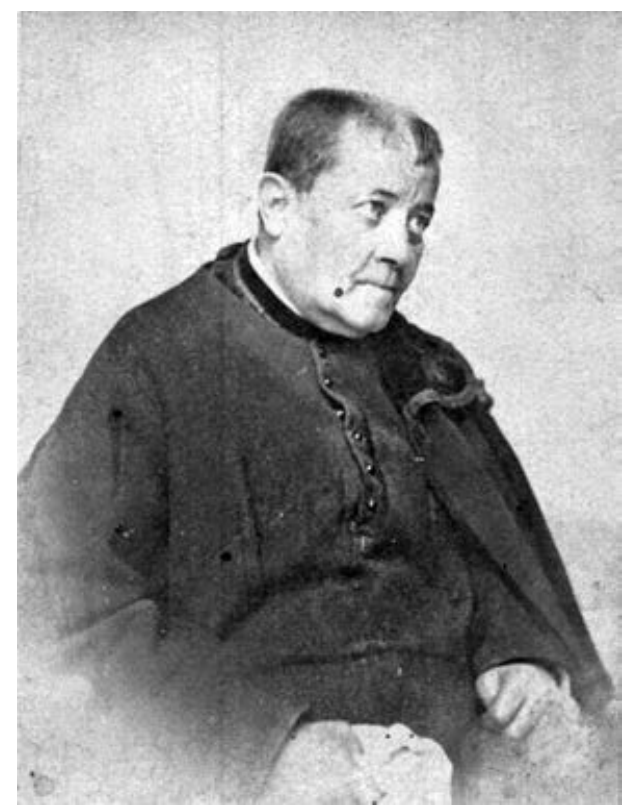

Fray Diego de la Concepción Palomar sin hábito, vistiendo sotana. FUENTE: CFCFNSG

seculares, ningún novicio podía hacerlo según la ley eclesiástica hasta que no profesara sus votos solemnes y pasara cuando menos cuatro años en el noviciado. El problema era que la ley del 12 de julio prohibía los noviciados, de manera que a lo largo de los siguientes años, a todos los novicios del país se les sugirió dirigirse a la Santa Sede para que les permitiera ordenarse como sacerdotes diocesanos. ${ }^{66}$

66 Rafael Venegas a Pelagio Antonio Labastida y Dávalos en Ciudad de México; Ciudad de México, 25 de enero de 1865, BNAH, RIIM, c. 3, doc. 696, ff. 1-2; Miguel María de la Luz Limas a Pelagio Antonio Labastida y Dávalos en Ciudad de México; Ciudad de México, 28 de abril de 1865, BNAH, RIIM, c. 3, doc. 698, ff. 1-2; Albino Francisco Velázquez a Pelagio Antonio Labastida 
A lo largo de la Guerra de Reforma, la ciudad de Zacatecas fue ocupada una y otra vez por los conservadores. Después de la exclaustración, González Ortega sólo pudo conservar la ciudad por algunos meses, hasta el 27 de octubre de 1859. En noviembre logró recuperarla, pero sólo por un lapso muy breve. Después de eso inició una administración conservadora, la cual duró hasta febrero de 1860 y permitió regresar a los religiosos de Guadalupe. ${ }^{67} \mathrm{El} 1^{\circ}$ de enero de 1860 el gobernador conservador de Zacatecas, Silverio Rodríguez, decretó la devolución del Colegio y sus bienes a la comunidad. Sin embargo, el 5 y el 6 de enero, sólo un puñado de religiosos volvió a enclaustrarse; muy probablemente quienes jamás salieron de Zacatecas. El grueso siguió en la Ciudad de México y en otros puntos. ${ }^{68} \mathrm{Al}$ poco tiempo, los liberales recuperaron la plaza y expulsaron a los pocos religiosos que regresaron al claustro. Pese a que los conservadores volvieron a ocupar la población, no se registró ninguna nueva inclaustración. ${ }^{69}$

Cuando a inicios de diciembre de 1860 los liberales se acercaron a Cholula, los religiosos tuvieron que abandonar también su Colegio y refugiarse en Puebla, donde el obispo les permitió alojarse en la Casa de Ejercicios de la Concordia. Al poco tiempo, cuando la comunidad tuvo noticia de la batalla de Calpulalpan del 22 de diciembre de 1860, y con ello de la derrota de los conservadores, fray Diego Palomar pidió permiso a la Santa Sede, y ya no a la Iglesia mexicana, para que se les autorizara a los

y Dávalos en Ciudad de México; Ciudad de México, 24 de mayo de 1865, BNAH, RIIM, 3, doc. 697, ff. 1-2; Miguel María de la Luz Limas a Pelagio Antonio Labastida y Dávalos en Ciudad de México; Ciudad de México, 3 de junio de 1865, BNAH, RIIM, c. 3, doc. 694, ff. 1-2; "Conducta de Fr. Diego de la C. Palomar”, AHFZ, CAG, Correspondencia de fray Diego de la Concepción Palomar, vol. I, p. 21.

67 Sánchez Tagle, ;Muera el ejército!, pp. 180-194.

68 "El Colegio de Guadalupe de Zacatecas", La Sociedad, 750 (22 ene. 1860),

p. 1; “Zacatecas”, La Sociedad, 753 (25 ene. 1860), p. 3.

69 SÁnchez TAgle, ;Muera el ejército!, p. 197. 
colegios de Propaganda Fide del país relajar los preceptos disciplinares de su regla y vivir como clérigos seculares hasta que las circunstancias les permitieran lo contrario. ${ }^{70}$ Entre el 13 y el 23 de diciembre de 1860, los guadalupanos acogidos en la Ciudad de México fueron provistos de prendas propias del clero secular. Dejaron San Fernando hasta las vísperas de Navidad, algunas horas antes de que González Ortega ocupara la plaza. Algo similar ocurrió con los guadalupanos de Puebla. Luego de esto, toda la comunidad se dispersó. La situación de los frailes de todo el país se tornó sumamente complicada. Los que insistieron en seguir vistiendo el hábito procuraron ocultarse bien. Tanto los de la Ciudad de México como los de Puebla fueron ayudados por algunos vecinos que acogieron en sus casas de uno hasta tres frailes. Luego de obtener licencia y de recaudar lo suficiente para viajar al interior, la mayoría pudo regresar con sus familiares. Una gran parte volvió a Zacatecas, otros se diseminaron en varios estados. Sólo tres permanecieron en la Ciudad de México y cuatro en Puebla. Algunos de ellos, como veremos más adelante, esperaron las condiciones para poder volver a enclaustrarse. ${ }^{71}$

Entre 1861 y finales de 1863, la mayor parte de los guadalupanos comenzó a olvidarse de la vida común y regresó con sus familias, adquiriendo algún trabajo o profesando el sacerdocio secular. Según Tiscareño, al menos tres exfrailes llegaron a renegar de sus votos. El mismo autor afirmó que muchos de los exclaustrados fueron favorecidos por "la suerte" y al poco tiempo adquirieron fortunas regulares. ${ }^{72}$ Pero el hacerse de riquezas

70 Tiscareño, El Colegio de Guadalupe, t. IV, pp. 43-45.

71 Carta anónima al Secretario de Gobierno de Jalisco en Guadalajara; Guadalajara, s/f; BNAH, RIIM, c. 3, doc. 401-1, ff. 1-2; EsparZa SÁNCHEZ, Compendio histórico del Colegio, pp. 96-97; TiscareÑo, El Colegio de Guadalupe, t. IV, pp. 45,65 .

${ }^{72}$ Lo contrario ocurrió en España, donde gran parte del clero regular terminó en la vagancia y viviendo de la caridad. Revuelta González, Política religiosa de los liberales, p. 332. 
no fue el caso de todos. Tomás Villanueva, un exdonado que se hallaba en Puebla para 1864, manifestó ser sumamente pobre y de avanzada edad para trabajar. Así, en 1867 recurrió al propio Benito Juárez para que lo socorriera. ${ }^{73}$

El destino de los miembros de la comunidad fue variado. Un hermano laico obtuvo indulto de secularización de Roma y permiso para casarse. Otros religiosos de Guadalupe continuaron dentro del clero regular de manera clandestina. Los que tuvieron dudas sobre cómo seguir respetando la regla, acudieron con fray Diego Palomar. Con licencia de la diócesis de Guadalajara, se dedicaron a administrar curatos y sacramentos, aunque dicha instancia les ordenó vestir como clérigos seculares. Vivían de las limosnas que recibían, que en ocasiones no les alcanzaban para sostenerse. Cuando se dirigían a la mitra para solicitar permisos o se escribían entre ellos, siguieron firmando como frailes. En 1861, fray Diego Palomar fue designado párroco de Zacatecas, fray José María Romo como su interino y a cuatro de sus hermanos se les eligió vicarios dependientes de la misma. De igual manera, el mismo año, fray Francisco de la Concepción Ramírez fue consagrado primer vicario apostólico de Tamaulipas, ${ }^{74} \mathrm{Juan}$ M. Munguía fue nombrado capellán de la iglesia de San Juan de Dios, Zacatecas, y el novicio Luis Zenón Corchado obtuvo indulto para ingresar al clero secular, consiguiendo ordenarse presbítero. Ya desde 1860, fray Palomar ordenó que todos los coristas que pudieran se ordenaran sacerdotes diocesanos, para evitar así problemas en el futuro. Así, por ejemplo, el 7 de octubre de 1862, el corista guadalupano Luis de la Concepción Soriano pudo solicitar a la mitra de Guadalajara ingresar al seminario diocesano. ${ }^{75}$

73 Tomás Villanueva Rodríguez a Benito Juárez en Ciudad de México; Ciudad de México, 26 de agosto de 1867, AGN, J, vol. 645, exp. 94, ff. 268-268v.

74 Años después fue ungido obispo de Caradra, Grecia.

75 Fray José María Romo al gobierno eclesiástico de Guadalajara; Zacatecas, 7 de abril de 1862, AHAG, $R$, c. 7, exp. 5, f. 670; fray Diego de la Concepción 
Al iniciar la Intervención francesa en México, algunos frailes guadalupanos vieron la oportunidad de volver a enclaustrarse. A los pocos meses de la toma de la Ciudad de México por el ejército francés, un puñado de hermanos de Guadalupe se reunió ahí para celebrar su capítulo. Eligieron a fray José María Romo como guardián de la comunidad errante, con visto bueno del comisario general, fray Diego Palomar. ${ }^{76}$ Cuando tuvieron la posibilidad, tras la ocupación francesa de Zacatecas en febrero de 1864, una parte de la comunidad regresó al Colegio de Guadalupe. Fray Palomar fue el primero en hacerlo junto con algunos religiosos. Sin aguardar autorización, volvió a vestir el hábito y tomó posesión del convento el 26 de julio de $1864 .{ }^{77} \mathrm{Su}$ ejemplo

Palomar al gobierno eclesiástico de Guadalajara; Zacatecas, 15 de abril de 1862, AHAG, $R$, c. 7, exp. 5, f. 672; fray Ignacio Ramírez Arellano al gobierno eclesiástico de Guadalajara; Guadalajara, 30 de agosto de 1862, AHAG, $R$, c. 7, exp. 5, ff. 674-674v.; fray Teófilo García Sancho a Buenaventura Auda en Tlaltenango; Guadalajara, 10 de octubre de 1862, AHAG, $R$, c. 7, exp. 5, ff. 675-675v.; AHAG, $R$, c. 7, exp. 5, ff. 674-674v.; Luis de la Concepción Soriano al gobierno eclesiástico de Guadalajara; Guadalajara, 7 de octubre de 1862, AHAG, $R$, c. 7, exp. 5, f. 676; fray Manuel Chacón a Jacinto López s/1; “casa de usted”, 16 de octubre de 1862, AHAG, $R$, c. 7, exp. 5, f. 678; Francisco de Paula Verea y González a fray Diego de la Concepción Palomar en Zacatecas; Roma, 26 de noviembre de 1861, AHFZ, CAG, Correspondencia de fray Diego de la Concepción Palomar, vol. I, s/ff.; TiscareÑo, El Colegio de Guadalupe, t. IV, pp. 9, 17, 295-297; Dávila Garibi, Apuntes para la historia de la Iglesia en Guadalajara, t. IV, p. 972.

${ }^{76}$ Esparza Sánchez, Compendio histórico del Colegio, p. 97.

77 Desde el momento en que los frailes fueron exclaustrados, el predio, las propiedades y los bienes del Colegio de Guadalupe iniciaron un proceso de cambio de manos. Pese a que quedaron al cuidado de algunos vecinos y de la mitra de Guadalajara, gran parte de sus bienes fueron extraídos por el gobierno y particulares. Sus terrenos fueron rematados. González Ortega pensó demoler el exconvento; sin embargo, el Congreso local solicitó al gobierno federal la cesión del edificio para establecer una escuela, lo cual se autorizó en febrero de 1862. Pese a ello, por la guerra, jamás pudo ser fundada (Juicio de 
fue seguido por otros frailes. Como argumento para retornar a la vida común alegaron que, en varios documentos, la Santa Sede les había recomendado que siempre que pudieran volver a su convento lo hicieran. Una vez en Guadalupe, fray Diego Palomar no hizo nada por retomar la fundación del Colegio de Cholula. No fue sino hasta que fray Francisco Cardona fue ascendido a comisario general, en 1865, que éste tomó la iniciativa de rehabilitar dicho Colegio. Envió como nuevo guardián a fray Guadalupe González junto con un puñado de novicios para que residieran en él, los cuales al poco tiempo profesaron. ${ }^{78}$

De los 116 guadalupanos exclaustrados en 1859, muy pocos volvieron a enclaustrarse. Para 1864, sólo 24 regresaron al convento, más un fraile incorporado del Colegio de Querétaro. De ellos, tres eran donados y el resto frailes, en su mayoría los más jóvenes. Siete de los frailes eran coristas, lo cual asombra, pues por órdenes del comisario general pudieron haberse convertido al clero secular. Los tres donados, por su parte, no tenían ninguna obligación de volver por no haber profesado votos. El resto de la comunidad no sólo no regresó al convento, sino que censuró la inclaustración de sus hermanos, alegando que dentro de poco serían echados nuevamente. Dichos ex religiosos guadalupanos se dispersaron en todo el país, ya fuese con sus familias o trabajando por su cuenta. Tiscareño y Sotomayor dieron parte

amparo promovido por el Lic. Kimball en representación de la familia García Elías contra el gobierno de Zacatecas, 8 de enero de 1870, AHSCJN, $A E$, c. 604, exp. 71,158; Francisco Delgado al jefe político de Zacatecas; Guadalupe, 30 de julio de 1859, AHEZ, JPZ, Correspondencia con las municipalidades, Guadalupe, c. 5, s/f.; “Zacatecas", La Sociedad, 753 (25 ene. 1860), p. 3; TiscaREÑo, El Colegio de Guadalupe, t. IV, pp. 10-11, 13; VIDAL, Continuación del bosquejo bistórico, t. I, pp. 70, 91; EsPARZA SÁnchez, "Historia de la ganadería en Zacatecas", p. 59.

${ }^{78}$ Fray Joaquín D. Cabrera a fray Diego de la Concepción Palomar en Guadalupe; San Miguel Allende, 22 de abril de 1864, AHFZ, CAG, Correspondencia de fray Diego de la Concepción Palomar, vol. I, s/f.; Tiscareño, El Colegio de Guadalupe, t. Iv, pp. 46-49, 294, 297. 
del destino de algunos. Informan que para 1864, un exdonado y 12 exfrailes, entre ellos el mencionado fray Luis Zubía, se avecindaban en casas particulares de la villa de Guadalupe. En la ciudad de Zacatecas se hallaban un exdonado y 11 exfrailes guadalupanos. En el resto del estado había 12 exfrailes más y un exdonado. Los demás encontraron hogar en otros estados, como Jalisco, Colima, Aguascalientes, Guanajuato, Michoacán y San Luis Potosí. En la Ciudad de México se quedaron a vivir tres exfrailes y en Puebla dos y un exdonado. Algunos de los exguadalupanos mencionados, pese a que no se volvieron a enclaustrar, vivieron una vida semirregular, como Bernardino de Jesús Pérez, quien para la década de 1870 residía en Tepozotlán y a veces vestía hábito dentro de su casa. ${ }^{79}$

La política del Segundo Imperio en torno a los frailes exclaustrados fue vacilante y ambivalente. Si bien Maximiliano señaló que dejaría al arbitrio del papa la decisión de restablecer las órdenes y prometió que todas las comunidades religiosas que aún existían podían continuar funcionando, no aceptó devolverles sus bienes a las hermandades. ${ }^{80}$ Tampoco anuló la ley del 12 de julio, sino que la siguió poniendo en práctica. En agosto de 1865, por ejemplo, Maximiliano fue informado de que los frailes de

79 Francisco de Paula Verea y González a fray Diego de la Concepción Palomar en Zacatecas; Roma, 26 de noviembre de 1861, AHFZ, CAG, Correspondencia de fray Diego de la Concepción Palomar, vol. I, s/ff.; fray Diego de la Concepción Palomar a José María del R. y Guerra en Guadalajara; Guadalupe, 8 de agosto de 1865, AHFZ, CAG, Correspondencia de fray Diego de la Concepción Palomar, vol. I, s/f.; Tiscareño, El Colegio de Guadalupe, t. IV, pp. 295-297; Sотомауов, Historia del apostólico Colegio, p. 385.

${ }^{80}$ Fray Joaquín María Morillos a fray Diego de la Concepción Palomar en Guadalupe; Puebla, 8 de enero de 1866, AHFZ, CAG, Correspondencia de fray Diego de la Concepción Palomar, vol. I, f. 5; Cuevas, Historia de la Iglesia en México, t. V, pp. 350-353; Knowlton, Los bienes del clero y la Reforma mexicana, pp. 162-205; GaLEANA, Las relaciones Iglesia-Estado durante el Segundo Imperio, pp. 67-75; "Índice de los expedientes que remite el Ministro de Justicia al Ministro de Relaciones Exteriores y Gobernación. Años de 18591861", en AGN, $J$, vol. 645, exp. 121, f. 321. 
Celaya habían vuelto a ocupar sus conventos, los cuales, pese a estar en remate, no habían sido comprados. El emperador, entonces, dispuso se echase a los frailes y que se lotificaran y vendieran sus propiedades. ${ }^{81}$

Pese a que los religiosos guadalupanos regresaron ilegalmente al Colegio, nadie hizo nada para expulsarlos. La comunidad tuvo que compartir el edificio con militares, que hasta 1867 ocuparon la mayor parte del convento como cuartel. A pesar de ello, pudieron oficiar en la iglesia y alojarse en una pequeña pieza anexa al templo. ${ }^{82}$ Aunque el gobierno imperial llegó a amenazar a los religiosos de Guadalupe para que se exclaustraran nuevamente, ${ }^{83}$ Maximiliano demostró cierta deferencia hacia ellos, llegando a recibirlos amablemente. Fray Francisco de la Concepción Ramírez fue miembro de su Concejo privado y su Limosnero Mayor. Anteriormente, había formado parte de la Junta de Notables que decidió traer al trono a Maximiliano. Fue así que, posiblemente para darles alguna utilidad a los guadalupanos, y de paso deshacerse de algunos, el emperador les encomendó una tarea en el extranjero, algo que hizo en otras ocasiones con individuos que no deseaba que sirvieran a su gobierno dentro del país. Los religiosos guadalupanos, dada la situación en que se hallaban, bajo la autoridad de un gobierno que en parte los seguía repudiando, aceptaron la tarea con entusiasmo. Ésta consistió en ir a Tierra Santa para "rescatar" el convento de la Santa Cruz de Jerusalén, todo bajo auspicio imperial.

81 "Reglamento para la exacta ejecución de la Ley del 5 de julio de 1865 referente a las operaciones de desamortización y rendición de bienes eclesiásticos", AGN, SI, c. 25, exp. 15, ff. 1-4; Ministro de Instrucción Pública y Cultos a la prefectura política de Celaya; Ciudad de México, 6 de septiembre de 1865, AGN, IPBA, vol. 612, exp. 1, f. 8; Administrador de bienes nacionalizados al Ministro de Instrucción Pública y Cultos en Ciudad de México; Ciudad de México, 9 de octubre de 1865, AGN, IPBA, vol. 612, exp. 1, ff. 11-12.

82 Tiscareño, El Colegio de Guadalupe, t. IV, pp. 295, 297.

83 Comisario general de los Colegios Apostólicos al ministro de Justicia en Ciudad de México; Zacatecas, 1866, AGN, JI, vol. 198, exp. 30, ff. 308-309. 
Con ello, el Imperio Mexicano pretendía mejorar sus relaciones con la Santa Sede. Dicha comisión la integraron seis religiosos de Guadalupe, presididos por fray José María Romo. De tal manera, cuando salió del país a principios de 1865, el convento perdió un número importante de integrantes de su reducida comunidad y a su guardián. Al llegar a Roma, Pio IX no aceptó la idea, de manera que los seis frailes pasaron a Tierra Santa sólo con licencia temporal. Al poco tiempo regresaron, salvo por fray Romo, a quien la Santa Sede encomendó la parroquia de Beirut. En adelante, y hasta su muerte, fue comisionado como guardián de conventos en Estados Unidos y Egipto. ${ }^{84}$

Durante esos años se presentó una segunda oportunidad para que los religiosos abandonaran el país. En marzo de 1865, el ministro general de la orden franciscana mandó a fray Palomar, en calidad de comisario general de los colegios de México, a fundar un Colegio en Costa Rica con ocho frailes. Palomar aceptó gustoso. Envió religiosos de Guadalupe y Zapopan, los cuales llegaron a Costa Rica a finales de 1866. Al poco tiempo, sin embargo, el intento fracasó por oposición del gobierno costarricense. ${ }^{85}$

Hacia los últimos meses de la Intervención francesa, conforme las tropas extranjeras evacuaban México, los liberales volvieron a exclaustrar a los religiosos que habían regresado a sus conventos. En Guadalupe ocurrió en noviembre de 1866, cuando los franceses evacuaron Zacatecas. Una vez más, la polémica y el descontento popular en torno a ello fueron mayúsculos. Meses después, no más de 20 guadalupanos entraron nuevamente al Colegio, conducidos por fray Juan Crisóstomo Gómez, quien volvió a vestir el hábito y fue guardián hasta su muerte, en 1882. La conducta de fray Gómez sorprende pues,

84 Tiscareño, El Colegio de Guadalupe, t. IV, pp. 309-312; Sotomayor, Historia del apostólico Colegio, pp. 344-347.

85 Picado Gatjens y Quirós Castro, Monseñor Víctor Manuel Sanabria, pp. 179-181; TisCareÑo, El Colegio de Guadalupe, t. IV, p. 298. 
como se mencionó antes, desde la primera exclaustración, comenzó a desobedecer a sus superiores. Además, renegó de usar hábito, volver al claustro, y conspiró en contra de los religiosos para que la iglesia del convento se erigiera como parroquia. Pese a todo ello, revistió el hábito en 1867 y por alguna razón fue elegido guardián de los guadalupanos. ${ }^{86}$

Otro grupo de frailes guadalupanos dejó definitivamente la vida regular en noviembre de 1866. El padre fray Alatorre, por ejemplo, a quien sus hermanos consideraban "buen religioso", decidió incumplir sus votos y retirarse a la vida privada. En palabras de Ignacio Mateo Guerra y Alba, primer obispo de Zacatecas, se volvió "devoto del dios Baco; [y aunque] se le ha llamado con los más suaves términos, [...] se ha excusado, sin decir terminantemente el motivo". ${ }^{87}$ Durante la presidencia de Sebastián Lerdo de Tejada, nuevamente fueron tomadas medidas estrictas para prohibir la vida comunal y vestir hábito. Varios conventos clandestinos se mandaron suprimir. En la ciudad de México se expulsó de casas ilegales a cerca de 70 frailes y jesuitas. ${ }^{88}$ El Colegio de Guadalupe, sin embargo, pudo continuar su vida en secreto. La población, que anteriormente se manifestó en su favor, continuó sirviéndolo y apoyándolo. El obispo de Zacatecas, cuya diócesis se erigió en 1864, les autorizó a los guadalupanos administrar sacramentos de bautismo y matrimonio

86 Jesús Ortiz a Ramón Corona en Guadalajara; Guadalajara, s/f, BNAH, RIIM, c. 3, doc. 464, ff. 1-4; comandante militar de Jalisco al vicario capitular en Guadalajara; Guadalajara, 31 de diciembre de 1866, BNAH, RIIM, c. 3, doc. 469, f. 1; fray Francisco Cardona a fray Diego de la Concepción Palomar en Guadalupe; Ciudad de México, 24 de junio de 1870, AHFZ, CAG, Correspondencia de fray Diego de la Concepción Palomar, vol. I, s/f.; Tiscareño, El Colegio de Guadalupe, t. IV, pp. 15-17, 375; SотомаYor, Historia del apostólico Colegio, p. 300.

${ }^{87}$ Ignacio Mateo Guerra y Alba a fray Diego de la Concepción Palomar en Guadalupe; Zacatecas, 5 de marzo de 1867, AHFZ, CAG, Correspondencia de fray Diego de la Concepción Palomar, vol. I, s/f.

${ }^{88}$ KnOwLton, Los bienes del clero y la Reforma mexicana, pp. 231-232. 
en su diócesis. Daban misa en la iglesia de Guadalupe sin colgar el hábito y recibían importantes donaciones de los vecinos, particularmente de la familia Miranda. ${ }^{89}$

Durante el porfiriato, el gobierno experimentó una suerte de conciliación con la Iglesia. ${ }^{90}$ Con tal de mantener este estado, se comenzó a tolerar la existencia de las comunidades religiosas. En ese sentido, no sólo se admitió por debajo de la mesa la existencia del Colegio de Guadalupe, sino que incluso se permitió que sus frailes consiguieran las escrituras de su terreno. En 1878, cuando se trasladó el Hospicio de la Bufa al Colegio, el gobierno firmó un convenio directamente con fray Juan Crisóstomo Gómez. Por medio de este acuerdo, se reconoció a los religiosos la posesión legal de la iglesia, de las capillas adyacentes, del cementerio, de la sacristía y del recinto del patio que sirve de entrada a la sacristía. A cambio, fray Gómez aceptó ceder al estado el resto del convento. Al poco tiempo, por 6000 pesos, los frailes adquirieron una parte importante de los claustros; sin embargo, perdieron varios metros cuadrados cuando en 1881 se estableció un asilo de niñas al lado del hospicio. La comunidad quedó finalmente reducida a tres claustros, la iglesia y sus anexos. ${ }^{91}$

En 1885 existían en México 346 franciscanos, 108 de ellos en seis Colegios de Propaganda Fide..$^{92}$ De los seis, el más poblado continuaba siendo el de Guadalupe, con 44 frailes, seguido por el de Cholula, con 20. Las comunidades de los otros cuatro eran inferiores a 15 individuos en cada uno. El Colegio de Cholula había pasado experiencias similares al de Guadalupe. Tras la

${ }^{89}$ Ignacio Mateo Guerra y Alba a fray Diego de la Concepción Palomar en Guadalupe; Zacatecas, 5 de marzo de 1867, AHFZ, CAG, Correspondencia de fray Diego de la Concepción Palomar, vol. ı, s/f.

90 Knowlton, Los bienes del clero y la Reforma mexicana, pp. 236-237.

91 Comisaría General de la Orden Franciscana en la República Mexicana, Estadística de la Comisaría, p. 34; Esparza Sánchez, Compendio histórico del Colegio, pp. 106-107.

${ }_{92}$ La comunidad del Colegio de Orizaba fue la única que la ley de exclaustración logró disolver por completo. 
nacionalización, perdió gran parte de su predio. En diciembre de 1891, los religiosos de Cholula fueron echados del claustro, acusados por el gobierno del estado de ocultar su vida común y un noviciado tras un colegio mariano de instrucción primaria. Los religiosos fueron conducidos al cuartel de policía de Puebla, al igual que los agustinos y carmelitas de la capital. Sin embargo, con motivo del descontento popular y del derrocamiento del gobernador, los religiosos fueron puestos en libertad y pudieron volver al claustro. ${ }^{93}$

El Colegio de Guadalupe y el de Cholula lograron sobrevivir hasta 1908, cuando se decretó su desaparición. El 19 de marzo de ese año, la Santa Sede giró la orden de suprimir los colegios de Propaganda Fide y fusionarlos a las provincias franciscanas. Así, el 26 de junio de 1908, el Colegio de Guadalupe fue convertido en un convento ordinario dependiente de la provincia franciscana junto con los conventos de San Francisco de Zacatecas y Santiago de Xalisco. La mayor parte de sus 31 frailes continuaron en la orden. Ángel Tiscareño, último guardián de Colegio, fue designado párroco de San Juan de Dios, Zacatecas. ${ }^{94}$

\section{CONCLUSIONES}

Desde la promulgación de la ley del 12 de julio de 1859, las comunidades religiosas de México pasaron momentos críticos. Algunas de ellas no lograron superarlos y desaparecieron. La experiencia del Colegio de Guadalupe es significativa, pues revela cómo una hermandad tan grande logró sobrevivir a un periodo apremiante de persecuciones utilizando una serie de estrategias que en ocasiones resultaron exitosas. Los guadalupanos tuvieron

93 Comisaría General de la Orden Franciscana en la República MexiCANA, Estadística de la Comisaría, p. 39; Tiscareño, El Colegio de Guadalupe, t. IV, p. 48.

94 Esparza Sánchez, Compendio bistórico del Colegio, pp. 101-102; VIDAL, Continuación del bosquejo bistórico, t. I, p. 325. 
que recurrir a todo tipo de tácticas, tales como huir de las autoridades liberales, ocultarse, establecer nuevas fundaciones, hacerse de oídos sordos, aparentar sumisión y, en general, desobedecer la ley. Todo ello lo hicieron a costa de un grave riesgo que no todos estuvieron dispuestos a asumir y que llevó a varios a desertar de la congregación. Así como hubo religiosos que se negaron a romper sus votos, resulta interesante que el grueso de la comunidad no tuvo ningún problema con violarlos ni con acoplarse a la vida civil. Sólo algunos pasaron al clero secular. A lo largo de sus futuras vivencias, los pocos frailes guadalupanos que continuaron en la orden tras 1860 tuvieron que adaptarse a nuevas reglas de juego político, completamente distintas a las que conocían. De tal forma, su relación con el gobierno y con la sociedad nunca volvió a ser la misma.

La hermandad de Guadalupe no sólo tuvo que enfrentarse al peligro de desaparecer. En plena Guerra de Reforma, se vio en medio del campo de batalla entre la Iglesia mexicana y el régimen liberal. Pese a que al gobierno eclesiástico de Guadalajara no le correspondía dar órdenes a la comunidad, acabó haciéndolo, toda vez que con ello buscaba cumplir un claro objetivo político y material: separar a los frailes de Zacatecas para desprestigiar a los liberales y hacerse de los bienes de la comunidad. Pese a que no hay pruebas de que el Colegio de Guadalupe apoyara económicamente al partido conservador, los liberales zacatecanos estaban conscientes de que nacionalizarlo y exclaustrar a sus religiosos resultaría útil para su causa. $\mathrm{Al} \mathrm{ob-}$ servar la ley del 12 de julio, sabían que conseguirían recursos y que desatarían un proceso que consideraban deseable y que sería complicado revertir, incluso si perdían la guerra. En efecto, aunque los conservadores hubiesen triunfado, la Iglesia difícilmente iba a poder recuperar todos los bienes que le fueron arrebatados.

Como pudimos ver a lo largo de este trabajo, en el caso del Colegio de Guadalupe, la ley de exclaustración no logró suprimir al clero regular. Lo que su promulgación provocó no fue 
sino una evolución de las comunidades religiosas en razón de nuevas exigencias políticas. Fue el comienzo de una época diferente para las órdenes, una en la cual tuvieron que moverse dentro de la ilegalidad, arriesgarse a ser perseguidas y, al mismo tiempo, brindar servicios a sus fieles con menor número de religiosos e infraestructura reducida. Si bien en el proceso perdieron a gran parte de sus hermanos y de sus propiedades, con el pasar de los años una porción de la comunidad del Colegio de Guadalupe logró sobrevivir los embates más extremos. Ya entrado el porfiriato, hacia 1898 , se tiene registro de la existencia de varias casas de religiosos toleradas en todo el país. Los obispos, por su parte, les otorgaban licencia para predicar y confesar en sus jurisdicciones. ${ }^{95}$

\section{SIGLAS Y REFERENCIAS}

AGN, IPBA Archivo General de la Nación, fondo Instrucción Pública y Bellas Artes, Ciudad de México, México.

AGN, $J$ Archivo General de la Nación, fondo Justicia, Ciudad de México.

AGN, JA Archivo General de la Nación, fondo Justicia Archivo, Ciudad de México.

AGN, JI Archivo General de la Nación, fondo Justicia Imperio, Ciudad de México.

AGN, SI Archivo General de la Nación, fondo Segundo Imperio, Ciudad de México.

AHAG, $R$ Archivo Histórico del Arzobispado de Guadalajara, fondo Religiosos, Guadalajara, Jalisco, México.

AHAM, SA Archivo Histórico del Arzobispado de México, fondo Secretaría Arzobispal, Ciudad de México, México.

AHEZ,JPZ Archivo Histórico del Estado de Zacatecas, fondo Jefatura Política de Zacatecas, Zacatecas, México.

AHFZ, CAG Archivo Histórico Franciscano de Zapopan, fondo Colegio Apostólico de Guadalupe, Zapopan, México.

AHSCJN, $A E$ Archivo Histórico de la Suprema Corte de Justicia de la Nación, fondo Asuntos Económicos, Ciudad de México, México.

95 Bautista García, Las disyuntivas del Estado y de la Iglesia, pp. 331, 333. 
BCRTA, Fot Biblioteca “Camino Real de Tierra Adentro”, fondo Fototeca, Guadalupe.

BNAH, RIIM Biblioteca Nacional de Antropología e Historia, fondo Reforma, Intervención e Imperio de Maximiliano, Ciudad de México, México.

CFCFNSG Colección Fotográfica del Convento Franciscano de Nuestra Señora de Guadalupe, Guadalupe, Zacatecas, México.

CMG Colección del Museo de Guadalupe, Guadalupe, Zacatecas, México.

Ahued Valenzuela, Salvador, El libro del histórico y virreinal Colegio Apostólico de Propaganda Fide de Nuestra Señora de Guadalupe de Zacatecas y convento franciscano del siglo XVIII, Guadalajara, Salvador Ahued Valenzuela, 1991.

Amador, Elías, Bosquejo histórico de Zacatecas, Zacatecas, Gobierno del Estado de Zacatecas, 1943, 2 tomos.

Bautista García, Cecilia Adriana, Las disyuntivas del Estado y de la Iglesia en la consolidación del orden liberal, México, 1856-1910, México, El Colegio de México, Universidad Michoacana de San Nicolás Hidalgo, 2012.

Bazant, Jan, Los bienes de la Iglesia en México, 1856-1875; aspectos económicos y sociales de la revolución liberal, México, El Colegio de México, 1996.

Cambre, Manuel, La Guerra de Tres Años. Apuntes para la historia de la Reforma, Guadalajara, Universidad de Guadalajara, 1986 [1904].

Carreño Velázquez, Elvira (coord.), Los libros en los senderos de la fe. Catálogo comentado de la Biblioteca del Colegio Apostólico de Propaganda Fide de Guadalupe, México, Apoyo al Desarrollo de Archivos y Bibliotecas de México, 2010.

Cázares Aguilar, Rocío y Francisco Mejía Sánchez, "Notas para la historia del Colegio Apostólico de Propaganda Fide de Cholula", en Román GutiérReZ et al. (coords.), 2008, pp. 299-312.

Comisaría General de la Orden Franciscana en la República MexiCANA, Estadística de la Comisaría General de la Orden Franciscana en la República Mexicana, Guadalajara, Tipografía de Ancira y Hno., 1885.

Connaughton, Brian, "De la tensión de compromiso al compromiso de gobernabilidad. Las Leyes de Reforma en el entramado de la política nacional", en Palacio y Connaughton (coords.), 2011, pp. 73-121. 
Covo, Jacqueline, Las ideas de la Reforma en México (1853-1861), México, Universidad Nacional Autónoma de México, 1983.

Crímenes de la demagogia. El Colegio Apostólico de Guadalupe en Zacatecas, México, Imprenta de José María Lara, 1860.

Cuevas, Mariano, Historia de la Iglesia en México, México, Porrúa, 1992, 5 tomos.

DÁvila Garibi, J. Ignacio, Apuntes para la historia de la Iglesia en Guadalajara, México, Cvltvra, 1967, 4 tomos.

Escandón, Patricia, "La estrategia imperial y los colegios apostólicos de América”, en Román Gutiérrez et al. (coords.), 2008, pp. 43-54.

EsparZa SÁnchez, Cuauhtémoc, "Historia de la ganadería en Zacatecas, 15311911”, en Zacatecas. Anuario de Historia, I (1978), pp. 12-160.

Esparza Sánchez, Cuauhtémoc, Compendio histórico del Colegio Apostólico de Propaganda Fide de Nuestra Señora de Guadalupe de Zacatecas, Zacatecas, Universidad Autónoma de Zacatecas, 1974.

Esparza Valdivia, Margarita Estela, Colegio y convento de Guadalupe: Imagen y descripciones. Siglos XIX y XX, Zacatecas, Universidad Autónoma de Zacatecas, Instituto Municipal de Cultura de Guadalupe, 2004.

Esparza Valdivia, Margarita Estela, Guia histórica de la Orden Franciscana Seglar de Guadalupe, Zacatecas, Zacatecas, s/ed., s/f.

Espinosa y Dávalos, Pedro, Carta pastoral que el Ilmo. Sr. Obispo de Guadalajara dirige a sus dioscesanos, con motivo de la Ley Penal publicada en Zacatecas en 16 de junio del presente año de 1859, Guadalajara, Tipografía de Dionisio Rodríguez, 1859.

Galeana, Patricia, Las relaciones Iglesia-Estado durante el Segundo Imperio, México, Universidad Nacional Autónoma de México, 1991.

Galindo y Galindo, Miguel, La gran década nacional, México, Instituto Nacional de Estudios Históricos de las Revoluciones de México, 2009, 3 tomos.

García Ugarte, María Eugenia, Poder político y religioso. México siglo XIX, México, Miguel Ángel Porrúa, 2010, 2 tomos. 
Gobierno eClesiástico de Guadalajara, Manifestación que hace el gobierno eclesiástico de Guadalajara, contra las disposiciones dictadas en Veracruz, Guadalajara, Tipografía de Dionisio Rodríguez, 1859.

González Quiñones, Armando (ed.), La biblioteca conventual del Colegio de Propaganda Fide de Nuestra Señora de Guadalupe, Zacatecas. Miscelánea de apuntes para su historia, Zacatecas, Instituto Zacatecano de Cultura, 2001.

Hale, Charles A., El liberalismo mexicano en la época de Mora, 1821-1853, México, Siglo Veintiuno Editores, 1972.

Knowlton, Robert J., Los bienes del clero y la Reforma mexicana, 1856-1910, México, Fondo de Cultura Económica, 1985.

López de LARA, José de Jesús, Guadalupe, guía de un viejo convento, México, Impresos Turísticos Religiosos, 1981.

MariÑo Jaso, Ana I., "Desamortización de bienes corporativos", en RuIz GuERrA (coord.), 2011, pp. 87-106.

Maza, Francisco, "El arte en la ciudad de Zacatecas", en Artes de México, viI (1949), pp. 5-16.

Mijangos, Pablo, Entre Dios y la República. La separación Iglesia-Estado en México, siglo XIX, Valencia, Tirant Lo Blanch, 2018.

Morales Valerio, Francisco, "Guadalupe Zacatecas. Actividad misionera de los franciscanos en un siglo de cambios”, en Román GutiérRez et al. (coords.), 2008, pp. 55-63.

Moreno Basurto, Salvador, "Una historia desangrada para un convento rosa. Historiografía de la exclaustración del Colegio de Guadalupe”, en Román GuTiÉRREZ et al. (coords.), 2008, pp. 329-338.

Palacio, Celia y Brian Connaughton (coords.), México durante la Guerra de Reforma, Xalapa, Universidad Veracruzana, 2011, 2 tomos.

Pérez Verdía, Luis, Historia particular del Estado de Jalisco. Desde los primeros tiempos de que hay noticia, hasta nuestros dias, Guadalajara, Escuela de Artes y Oficios del Estado, 1910, 3 tomos.

Picado Gatjens, Miguel y José Alberto Quirós Castro, Monseñor Víctor Manuel Sanabria. Estudios historiográficos, San José, Universidad Estatal a Distancia, 2006. 
Revuelta González, Manuel, La exclaustración, 1833-1840, Madrid, Editorial Católica, 1976.

Revuelta González, Manuel, Política religiosa de los liberales en el siglo XIX. Trienio constitucional, Madrid, Escuela de Historia Moderna, 1973.

Román Gutiérrez, José Francisco et al. (coords.), Los Colegios Apostólicos de Propaganda Fide. Su historia y su legado, México, Gobierno del Estado de Zacatecas, Universidad Autónoma de Zacatecas, H. Ayuntamiento de Guadalupe, 2008.

Ruiz Guerra, Rubén (coord.), Miradas de la Reforma, México, Universidad Nacional Autónoma de México, 2011.

SÁnchez Tagle, Héctor, ;Muera el ejército! Reforma liberal y guerra civil en Zacatecas (De Ayutla a Calpulalpan), Zacatecas, Instituto Zacatecano de Cultura "Ramón López Velarde", Ciudad y Memoria, en Cindad y Memoria, I: 5 (2014), pp. 7-349.

Sescosse, Federico, El Colegio de Guadalupe de Zacatecas. Escuela de misioneros y semillero de mártires, 1706-1993, México, Fondo Cultural Bancen, Ediciones del Equilibrista, 1993.

Sotomayor, José Francisco, Historia del apostólico Colegio de Nuestra Señora de Guadalupe de Zacatecas, Zacatecas, Imprenta La Rosa, 1889, 2 tomos.

Speckman, Elisa, "Las órdenes femeninas en el siglo xix: el caso de las dominicas", en Estudios de Historia Moderna y Contemporánea de México, 18 (1998), pp. 15-40.

Speckman, Elisa, "Congregaciones femeninas en la segunda mitad del siglo XIX”, tesis de maestría en historia, México, Universidad Nacional Autónoma de México, 1996.

Speckman, Elisa, "Los conventos de monjas y las leyes de febrero de 1861", tesis de licenciatura en historia, México, Universidad Nacional Autónoma de México, 1992.

Tena Ramírez, Felipe (comp.), Leyes fundamentales de México, 1808-2005, México, Porrúa, 2008.

Tiscareño, Ángel de los Dolores, El Colegio de Guadalupe. Desde su origen hasta nuestros días, México, Imprenta de José María Mellado, 1902-1909, 4 tomos. 
Torre Curiel, José Refugio de la, Vicarios en entredicho. Crisis y desestructuración de la provincia franciscana de Santiago de Xalisco, 1749-1860, Guadalajara, El Colegio de Michoacán, Universidad de Guadalajara, 2001.

Torre Curiel, José Refugio de la y Jesús Asdrúbal Ruiz Alcalá, “La provincia franciscana de Santiago Xalisco, 1824-1860", tesis de licenciatura en historia, Guadalajara, Universidad de Guadalajara, 1997.

VALDÉs, Manuel, Memorias de la Guerra de Reforma. Diario del coronel Manuel Valdés, México, Imprenta y Fototipia de la Secretaría de Fomento, 1913.

VIDAL, Salvador, Continuación del bosquejo histórico de Zacatecas del señor Elías Amador, Aguascalientes, s/ed., 1959, 2 tomos. 
